Eduardo Silva Arévalo, S.J.

Profesor de la Facultad de Teología

Pontificia Universidad Católica de Chile

\title{
Auscultar los signos del tiempo presente y de la situación latinoamericana. Esbozo de algunos fenómenos a considerar para una interpretación teológica del presente
}

Interpretar teológicamente la realidad, descubrir la significación teológica de los acontecimientos, discernir los signos de los tiempos, interpretar la praxis a la luz del evangelio son distintos modos de decir que la realidad, toda realidad, cualquier realidad humana, es portadora de sentido divino, tiene sentido en el camino del hombre y la mujer hacia Dios (1). Es tarea de la teología desentrañar ese sentido, que es uno -y no el único sentido- que la realidad tiene. La significación teológica, creyente, cristiana, espiritual, religiosa de la realidad, no acaba con la significación económica, política, psicoanalítica, estética, histórica y ética de la realidad. Más aún todos esos sentidos, esas significaciones son relevantes y pertinentes a la lectura teológica. "Si Dios es el Creador del Universo y el Señor de la Historia, nada de lo humano puede sernos ajeno. No se encuentran en la historia territorios sagrados y otros profanos; todos son portadores de sentido en el camino de la humanidad hacia Dios" (2).

Los distintos sentidos y significaciones que la realidad tiene, captados por las distintas aproximaciones a lo real, son condición de posibilidad para el quehacer teológico, pero no condición suficiente para su tarea. No puede prescindir de los datos e interpretaciones que ofrecen otras disciplinas en su aproximación a lo real (en una especie de deducción que habla solo desde la revelación), pero tampoco puede reducir su mirada teológica a los datos e interpretaciones que le suministran las otras disciplinas (en una especie de inducción o dependencia de análisis que simplemente sanciona). "Ni aplicación de principios previamente determinados a una situación histórico concreta. Ni la disolución liberal de la teología en la supuesta univocidad de los datos que sobre el presente pueden aportar otras ciencias. Ni la vía 'deductiva' del realismo sobrenaturalista ahistórico ni el procedimiento 'inducti-

(1) En esta introducción retomamos ampliándolas algunas de las afirmaciones presentes en J. Costadoat y E. Silva, "Interpretación teológica del presente", publicado en este mismo número.

(2) Raúl González, "Variables en el discernimiento histórico", ITER No 33 (2004) 77-105. En lo que sigue tomamos con libertad los aportes que este filósofo jesuita latinoaméricano nos ofrece a través de este artículo. 
vo' del realismo liberal. Lo primero renuncia a captar el presente en su positividad; lo segundo esfuma la positividad teológica" (3). Una teología auténtica debe evitar, "por una parte la pretensión de querer construir un sistema de la pura doctrina cristiana fuera de toda situación histórica, por otra, la simple reducción del mensaje cristiano a una situación cultural dada" (4).

La teología propone entonces una circularidad hermenéutica entre el mensaje cristiano y la situación actual, que aspira a terminar con toda yuxtaposición entre estos mismos polos que parecen constituirla, pues la acción de Dios se verifica en determinados signos discernibles en la historia, y la interpretación de esos signos nos permiten reconocer a Dios actuando en ellos. De la misma manera determinados signos, en vez de ser testimonio de Dios son obstáculos a su acción, y si no se denuncian y desenmascaran como tales, nos seducen y alejan de lo que Dios quiere y alienta en nosotros. Pero si toda la realidad nos aleja o acerca a Dios, ¿qué aspectos de ella son hoy más relevantes, qué acontecimientos son los más significativos?

Los signos que tenemos que mirar, las voces que tenemos que atender, los aspectos de la realidad que merecen nuestra atención de creyentes y teólogos son los que resultan más significativos para la vida plena del hombre, porque la favorecen o la dificultan. Lo más significativo para Dios es aquello que es más significativo para el hombre. Con ese criterio hemos procurado elegir las temáticas que han estado trabajando los cuatro equipos del Centro Teológico Manuel Larraín. Cuatro dimensiones de la realidad que nos parecían relevantes, temáticas claves, transformaciones de las que no podíamos dejar de hacernos cargo: la democracia como desafío y con ella el problema de la libertad, la exclusión como desafío a la fraternidad y a la virtud incluyente del Evangelio, las transformaciones actuales en la experiencia religiosa y las transformaciones vividas por propio catolicismo en el continente.

Estos cuatro temas no son simplemente, para la mirada creyente, fenómenos humanos, transformaciones culturales, desafíos seculares, que es bueno que ella comprenda, para adaptar mejor el evangelio que tiene que anunciar en este nuevo contexto, democrático, lleno de exclusiones y cambios religiosos y eclesiales. Estos cuatro temas - como otros que configuran nuestro actual contexto- no son un polo externo al mensaje cristiano, un afuera que conviene tener en cuenta, un punto de referencia anterior al anuncio del Evangelio y a los datos de la fe. Este extrinsecismo entre mensaje cristiano y situación contemporánea no es teológicamente sostenible. El sentido teológico de la realidad no se agota en los otros sentidos, pero requiere de ellos para ser descubierto. Elegir algunos signos, auscultarlos, interpretarlos premunidos de algunas hipótesis y opciones es comenzar a hacer teología. Pues no solo debemos elegir algunos signos sino que también las

(3) Juan Noemi, "La contemporaneidad de la teología. El ejemplo de Paul Tillich", Teologia y Vida 17 (1976) 96-97.

(4) Jean Richard, "La théologie comme herméneutique chez Claude Geffré et Paul Tillich", Interpreter, Du Cerf, Paris, 1992, 77. En esta circularidad entre mensaje y situación, reconocemos el método teológico de la correlación y la definición de la teología como "una empresa hermenéutica de punta a cabo". 
disciplinas, las mediaciones analíticas que nos permitan analizarlos y desentrañar sus múltiples sentidos. Junto a la elección de las perspectivas más adecuadas, conviene también elegir un buen lugar. ¿Desde dónde mirar? La mirada nunca es neutra, siempre ocurre desde algún lugar, desde alguna situación. Más bien desde varias situaciones. Las situaciones predeterminan la mirada. No se da realmente un proceso lineal, sucesivo, como lo insinuaba el clásico método del "ver, juzgar y actuar". Siempre miramos desde nuestros juicios, prejuicios, creencias y siempre juzgamos desde una determinada práctica, desde determinados compromisos. Por ello si bien los signos de los tiempos que aquí auscultamos e interpretamos requieren de un ulterior trabajo teológico, ya han sido elegidos y leídos desde una precomprensión teológica. Nuestros juicios los hacemos desde el don de la fe en la comunidad eclesial. Nuestra práctica quisiera ubicarnos desde un compromiso y cercanía con los más pobres y desfavorecidos (5).

Proponemos una mirada sobre el presente y la situación actual. Presente y situación aluden respectivamente nuestro tiempo y a nuestro lugar. Presente, como categoría temporal, nos habla del momento histórico, y nos remite inequívocamente a la actual fase de desarrollo de la modernidad. Situación, como categoría espacial, aludir al sitio, al suelo, a nuestro contexto latinoamericano, a sus peculiaridades culturales. Interesados como estamos por "nuestra situación en este presente", nuestra preocupación atenderá a lo local, lo peculiar, lo particular latinoamericano (II) en referencia a lo global, a lo universal, al actual estado de la modernidad (I). Si bien estas dos primeras partes no podrán dejar de relacionar el tiempo presente con la situación continental, los fenómenos globales con los fenómenos locales, los procesos de modernización con las identidades culturales, es en la tercera parte donde explícitamente los vincularemos desde el aporte que esta llamado a dar el catolicismo latinoamericano a nuestra peculiar trayectoria a la modernidad (III) (6).

(5) Preocupaciones teológicas han orientado la elección de los fenómenos que nos parecen más significativos; preocupaciones eclesiales afines al esfuerzo del Concilio motivan este intento de diálogo con las cuestiones más acuciantes de nuestro tiempo y situación; pero para el análisis de estos fenómenos hemos recurrido a los aportes que nos suministran las ciencias sociales, la sociología, la fenomenología de la religión y las reflexiones que nos ofrecen la filosofía política y la ética. Sin embargo, complementario a este nivel en el que hemos insinuado algunas hipótesis y esbozado algunos fenómenos, quedan pendientes un par de tareas fundamentales: una reflexión explícitamente filosófica sobre estas cuestiones (que aquí se ha dejado inspirar por los aportes de Paul Ricoeur y Charles Taylor), para poder realizar una interpretación explícitamente teológica sobre nuestro presente histórico concreto.

(6) Nuestras reflexiones deben mucho al trabajo de los equipos interdisciplinares del Centro Teológico Manuel Larraín, que he podido seguir de cerca y al proyecto de investigación en filosofía política que desarrollamos académicos de UAH. Junto a ellos las ponencias y discusiones sostenidas en el equipo jesuita de reflexión filosófica latinoamericana han sido decisivas en la confección de estas líneas 


\section{INTERPRETAR EL TIEMPO PRESENTE: LA TRANSFORMACIÓN DE LA MODERNIDAD}

\section{Modernidad y catolicismo: dos tradiciones en conflicto y en transformación}

Se ha vuelto un lugar común contraponer a conservadores y liberales, situando de un lado las posturas religiosas, confesionales, tradicionales y del otro las seculares, laicas, progresistas. Si bien se trata de etiquetas fáciles y estereotipos que suministran identidad a un pensamiento progresista que se siente en lucha contra un pensamiento católico que se opone a sus renovadas banderas de emancipación, son reflejo a su vez de un largo incordio desde que la cosmovisión moderno burguesa vino a remplazar a la cosmovisión antiguo medieval. Una larga batalla en las que es posible reconocer fenómenos tan diversos como el paso del Ancien Regime al nuevo orden gracias a varias revoluciones entre las que destaca la Revolución Francesa; o como la lucha entre "ilustrados y románticos", entre el "gesto crítico" que desenmascara y sospecha y el "gesto humilde" que se reconoce deudor de una tradición (7); o como las peleas entre el clero y los liberales que atravesaron el nacimiento de los estados independientes durante el XIX en América Latina (8). Revolución Francesa, Ilustración, Independencia parecen ser grandes hitos de una lucha entre las fuerzas libertarias que enarbolan la Razón y las resistencias conservadoras que se nutren de la Revelación. Frente a ellos, nuestras escaramuzas criollas ente una agenda liberal progresista y la defensa de los valores morales, no son más que la repetición, en términos psicoanalíticos, del trauma que da origen a la modernidad.

Creemos que están dadas las condiciones para salir de esta lastimosa repetición, de modo que catolicismo y modernidad en vez de estar obligados a enfrentarse irremediablemente, pueden ser llamados a fecundarse mutuamente, al punto que del catolicismo solo se puede esperar que sea moderno y de que aspiramos a que la modernidad sea renovada con lo mejor del catolicismo. Hablar de un catolicismo moderno y de una modernidad católica es exponerse a una serie de equívocos y malas interpretaciones que pueden confundir a unos y a otros, pero podrían llegar a ser orientadoras en medio de un mar de incertidumbres y de excesos de seguridad que acosan tanto a la barca de Pedro como al ideario moderno. Nuestra insistencia en vincular catolicismo y modernidad no es casual ni inocente, pues tenemos en cuenta, por un lado, la persistencia de una mentalidad precrítica al interior de vastos sectores del catolicismo, y por otro, el difundirse en los últimos años las aporías y la

(7) Las expresiones son de Paul Ricoeur en su intento de mediación entre la hermenéutica de las tradiciones y la crítica de las ideologías, en un debate que alude a las posiciones respectivas de Gadamer y Habermas. Volveremos sobre este debate más adelante, pues se trata de un intento de medición análogo al que aquí intentamos entre modernidad y cristianismo.

(8) El juicio sobre los grupos independentistas mexicanos es extensible a toda América latina: "Los intelectuales liberales asumieron el ideario ilustrado; la tolerancia religiosa, los derechos individuales, la libertad intelectual... La libertad y el progreso son los temas obligados, así como la fe en la razón para organizar la nueva sociedad sociopolítica... Los liberales promulgan (...) Leyes (...) destinadas a acabar con los fueros y con el poder de la Iglesia" (María Teresa de la Garza, Política de la memoria. Una mirada sobre Occidente desde el margen, Universidad Iberoamericana, Anthropos, México, 2002, 57-58). 
crisis de la modernidad en el equívocamente llamado posmodernismo (9). Curiosamente, en algunos ámbitos eclesiales los defensores de lo primero, apuestan con más ingenuidad que lucidez a los cantos de sirena de los profetas de lo segundo, en una clara alianza que no tiene otro objeto que denostar a una modernidad herida, haciendo leña del árbol que les parece ya caído. No deja de sorprender que en el Documento de Santo Domingo se alabe "la apertura a la trascendencia propia de la posmodernidad", con más ganas de que así sea que con realismo de lo que ella es (10).

Una crítica indiferenciada a la modernidad que pretenda contraponerla sin más con la cultura cristiana, además de falsa demoniza peligrosamente la historia y se aleja del reconocimiento de la creación como obra de Dios. La "ruptura entre Evangelio y cultura" que según Pablo VI es "el drama de nuestro tiempo" (11), invita a la Iglesia a mirar "con preocupación la fractura existente entre los valores evangélicos y las culturas modernas" (12), pero nunca a sentenciar la incompatibilidad entre el cristianismo y una cultura determinada (13).

La tradición republicana, liberal, ha sido fundamental en estos siglos de construcción de nuestras identidades nacionales. Sabemos que este proceso ha sido llevado a cabo a veces en contra, otras veces recibiendo el rechazo de la tradición católica que ha contribuido también a fraguar la identidad novohispánica del continente, y que permanece como un signo identitario clave de lo que significa ser latinoamericanos. No son pocos los que han sostenido que la modernidad consiste justamente en acabar con las culturas tradicionales, en un tránsito no pocas veces cuasi compteano, positivista, lineal y darwinista en el que la civilización supera a la barbarie. Igualmente sabemos que debido a ello, o a otras razones, no pocos católicos sostienen que es "la adveniente cultura moderna secularizada" la mayor amenaza que pende sobre nuestro continente, justamente porque corroe el sustrato católico que da identidad a nuestros pueblos.

En mi opinión este largo debate que en el continente ha tomado la forma de una querella entre modernidad e identidad cultural, se ve superado por la nueva situación que impone el fenómeno de la globalización y los intentos de construcción de sociedades sin atributos. Tal como la caída de la teoría de la dependencia obliga a buscar nuevos derroteros a un discurso social como el de la Teología de la Liberación que se quedó sin mediaciones analíticas, las propuestas de nueva evangeliza-

(9) Cfr. J. Noemi,

(10) Voces que parecen entusiasmarse con el permiso concedido por Kart Barth cuando afirma que podemos permitirnos ser más románticos que los románticos. Recordando este permiso Jean Greisch sugiere más bien que "en una coyuntura intelectual donde la palabra "posmoderna" está en todos los labios, ha llegado quizás la hora de proclamar alto y fuerte que podemos ser más modernos que los modernos!" (J. Greisch, Le Buisson ardent et les Lumières de la raison. L'invention de la philosophie de la religión. Tomo II. Les approches phénoménologiques et analytiques, Paris, Cerf, 2002,9).

(11) Evangelii nuntiandi, 20.

(12) "Discurso Inaugural del Santo Padre", Santo Domingo-1992. Nueva Evangelización, Promoción humana, Cultura Cristiana, 21.

(13) Los textos de Santo Domingo evitan, aunque rozan tal sentencia: "La ausencia de esos valores cristianos fundamentales en la cultura de la modernidad no solamente ha ofuscado la dimensión de lo trascendente, abocando a muchas personas hacia el indiferentismo religioso -también en América Latina-, sino que, a la vez, es causa determinante del desencanto social en que se ha gestado la crisis de la cultura"... (Ibíd., 21). 
ción y de inculturación de la fe pueden ser estériles si no son capaces de discriminar entre el proyecto moderno y el actual proceso en curso. Nuestra apuesta es que el conflicto entre tradición moderna y católica, puede transformarse en alianza y mutua fecundación, dada las nuevas condiciones que nos impone el ethos de la globalización. Como siempre ha sucedido en la Iglesia, a la luz de adversarios mayores, es probable que los enemigos de hoy sean los aliados del mañana.

Somos crecientemente conscientes que tanto el catolicismo como la modernidad no son modelos o nociones unívocas condenadas a enfrentarse, sino más bien realidades plurales y llenas de articulaciones entre ambas. Análogo al proceso de pluralización del fenómeno religioso y del catolicismo en particular (de lo que nos ocuparemos en la segunda parte), también la modernidad se dice de muchas maneras, y se habla de "múltiples modernidades", de "modernidades entramadas" o de "distintas fases de la modernidad". Las teorías más recientes han preferido denominar lo que la moda parisina llamó posmodenidad con los conceptos de "modernidad tardía" (A. Giddens), "modernidad reflexiva" (Ulrich Beck) que refieren a una segunda modernidad o a "una 'segunda fase de modernización de la sociedad moderna', un proceso de radicalización que termina por producir un nuevo tipo de capitalismo, de trabajo, de sociedad, de subjetividad, de orden global, etc.”. (14). Si en los países desarrollados del norte se da esta diferencia entre dos modernidades, la segunda transformando instituciones muy centrales de la primera, en los países donde no existe la primera modernidad (parte de África y Asia) o existe a medias (América Latina) se puede afirmar "que hay posibles trayectorias no europeas a la segunda modernidad" (15) y preguntarse por las peculiaridades (o diferencias o específicos) de la trayectoria latinoamericana a la modernidad. Al hacerlo es posible observar las diferencias por ejemplo en Chile entre "la etapa de modernización centralizada y protegida" que llega a su fin en los años 70 y los procesos de modernización (neo) liberales de la globalización actual. El interés de lo dicho está en subrayar que la modernidad "no puede entenderse como un proceso unilineal, preestablecido o cuasi natural cuyos objetivos son indiscutibles y claros. Toda modernización es un campo interpretativo y, en esa misma medida, un campo de lucha... no se trata de un proceso neutral que ocurre a pesar de los seres humanos y sus convicciones" (16). No se trata del despliegue implacable de un modelo único sino de una construcción social multiforme, fruto de todas las tradiciones y peculiaridades culturales de cada lugar. "Esta visión... permite resituar la larga discusión... acerca de si América Latina es moderna o no, o acerca de si puede llegar a serlo o de si es bueno que lo sea" (17).

\section{La globalización y sus dos caballos desbocados: capitalismo e individualismo}

En esta trayectoria latinoamericana a la modernidad la instalación del ethos de la globalización no solo impacta a las culturas tradicionales, sino también ha afectado el propio ideario moderno, al punto que podemos sostener, por ejemplo que la

(14) Jorge Larraín, ¿América Latina moderna?, LOM, Santiago, 2005, 15.

(15) Ibíd., 16.

(16) Ibíd., 26.

(17) Ibíd., 25. 
trayectoria chilena hacia la modernidad, parece consistir en un proceso de "modernización sin modernidad" (18).

En el complejo proceso de globalización en curso quisiera destacar dos fenómenos, utilizando una metáfora que más allá de sus simplificaciones nos permite visualizar mejor lo que está sucediendo. En lugar del fantasma que antaño recorría Europa hoy día dos caballos corren desbocados (19) a nivel planetario: el capital globalizado y el individualismo de la autorrealización. Dos fenómenos globales provocados por occidente y que afectan a todo el planeta. El primero de carácter económico político, a la vez que concentra la riqueza y excluye de sus beneficios a pueblos enteros, contribuye a acrecentar la injusticia y la inequidad; el segundo de carácter más cultural, al tiempo que erosiona los vínculos y pone en crisis las pertenencias, parece dificultar la creencia y confianza en otros y en Otro. Dos signos a nivel planetario que la preocupación por el servicio de la fe y la promoción de la justicia no podrían ignorarlos.

Respecto del primer corcel, el proceso de globalización ha implicado que el capital (20), fundamentalmente el financiero, viaje sin control de un lugar a otro del orbe. La inexistencia de una institucionalidad política a nivel planetario permite esta libertad. Algo similar a lo ocurrido con el capital hace más de 150 años: su aparición fue igual de desbocada hasta que lentamente la institucionalidad al interior de las naciones fue capaz de domesticarlo y someterlo. Un claro ejemplo son las socialdemocracias europeas que con normas, restricciones, leyes fueron capaces de proteger los derechos y deberes de aquellos que deseaban vivir juntos al amparo de un estado que velaba por todos los ciudadanos particularmente por los más débiles. La creación del estado, del estado de derecho, es en definitiva el sometimiento de lo económico a lo político. La crisis actual del Estado ha sido insistentemente diagnosticada y sus esfuerzos por adaptarse a la nueva situación hacen parte de esa crisis (21). Hoy las naciones, aptas para controlar los capitales nacionales son impotentes

(18) Enzo Solari, Samuel Yáñez, "El caso chileno: modernización sin modernidad”, en Sombras del Chile actual: una contribución filosófica, en Revista de Derecho No 10, Universidad católica del Norte, 2003, 201-219.

(19) La imagen de un mundo desbocada es también utilizada por Ulrich Beck, "Vivir nuestra propia vida en un mundo desbocado: individuación, globalización y política", Will Hutton y Anthony Giddens (eds.), En el límite. La vida en el capitalismo global, Tusquets Editores, 2000, pp. 233-245.

(20) "En cette fin de siècle, le capitalisme connaît en effet une expansion qui n'a pour but qu'ellemême (c'est-à-dire ses propres mécanismes de valorisation) et se retrouve dominée par la rivalité des pays du triangle (États-Unis, Europe de l'Ouest, Japon). Dans ce contexte, les problèmes des trois quarts de l'humanité deviennent secondaires. Le capitalisme est prospère, mais il avance comme un homme ivre qui sème les ruines sur son passage en Afrique, en Amérique Latine, en Asie et chez les laissés-pour-compte du développement dans les pays occidentaux. Toutefois dans sa réussite apparente, il montre ses propres limites ". (Jean Marie Vincent, "Capital et technoscience "Futur anterieur, 1990 pag www)

(21) "Par de telles pratiques l'État se soumet peu à peu aux processus et aux mouvements erratiques du capital transnational. Il ne règle plus les problèmes en fonction des équilibres nationaux à établir, mais en fonction des équilibres et déséquilibres internationaux. Ainsi, il devient progressivement un instrument de la mondialisation et de l'érosion des pratiques politiques nacionales". Frente a esta situación, una reacción equivocada sería pretender una vuelta al Estado-providencia, que es imposible como lo es también una economía nacional autónoma. Si es posible en cambio impedir que el Estado y sus aparatos sean meras cadenas de retransmisión del capitalismo internacional, y posibilitar que agrupación de Estados puedan generar algunas lógicas sociales diversas a las lógicas económicas del actual capitalismo tardío. "Autrement dit, lutter efficacement autour 
para controlar este nuevo capitalismo de nivel global. La tarea por tanto del presente, quizás, por los próximos 150 años, es crear las estructuras políticas a nivel planetario que permitan domesticar este capital globalizado que transita, cual golondrinas, sin ley ni Dios, hundiendo o fortaleciendo a su paso las vulnerables economías nacionales (22).

Respecto del segundo caballo desbocado, el del individualismo de la autorrealización, ha sido objeto de atención de muchos autores. Cercano al proceso de autonomía que permite a cada uno elegir por sí mismo (ser individuos libres es una conquista que enorgullece a la modernidad), nos referimos más bien a la atomización social, a lo que se ha denominado la "generación del yo" o la preeminencia del "narcisismo" (23). Un proceso que se estima irreversible, y que significaría que en nombre de la libertad individual, crecientemente todos los sujetos del planeta irán construyendo su propia identidad a partir de sí mismos. Cualquiera sea el futuro de las tradiciones, de los colectivos, de las comunidades, incluidos por cierto las religiones, las iglesias, las confesiones, ellas ya no tendrán nunca más fieles incondicionales, sino simpatizantes evaluadores (24). La relación de esas tradiciones con sus adeptos o afiliados ya no podrá ser de coacción sino de seducción. La condición de posibilidad de la pertenencia está en una pertenencia libre y en conciencia. Este proceso que pudiera ser atribuible al liberalismo político, que solo reconoce derechos de individuos que se estima iguales, pues sus diferencias quedan relegadas a la esfera privada, se radicaliza con el liberalismo económico, que ya no reconoce sujetos y con la globalización, que disuelve el cuadro de los Estados-nacionales. Frente a esta sistemática ruptura de lazos sociales, se comprende la reacción comunitaria y comunitarista que estima que el orden liberal individualista no sirve para determinar el bien común y los rasgos de una vida buena, para generar tejidos sociales, identidades colectivas, pertenencias y vínculos comunitarios (25). Se comprenden también los deseos de un resurgimiento de lo comunitario y de una revaloración de la familia y la nación, en la propia tradición liberal, que intenta apoyar la modernización, el mercado, y la modernización pero se declara en "contra de un orden individualista-mercantilista que socava los valores, certidumbres y sueños en los que se funda la vida en común" (26). Se comprenden también los esfuerzos por ponerle riendas adecuadas también a este caballo desbocado, pues individuos sin

de l'État national exige de dépasser les optiques étroitement nationales et d'organiser des convergences transnationales pour inverser des politiques et en imposer d'autres. Il ne peut plus y avoir de politiques nationales positives qui ne soient des politiques à visées transnationales (par exemple luttes sur l'emploi ou la spéculation financière)". (J. M. Vincent, "Au delà de l'Etat nation", Futur anterieur, 1995 pág. www).

(22) Cf. Raúl González, s.j., en XXII Encuentro del equipo jesuita latinoamericano de reflexión filosófica, San Salvador, julio 2005.

(23) Cf. Charles Taylor, Etica de la autenticidad, Paidós, Barcelona, 1994, 39-40; Ver también del mismo autor "L'atomisme", en La liberté des modernes, PUF, Paris, 1997, 223-254.

(24) Según Pedro Güell de una "credibilidad por fusión o adhesión" se pasa a una "credibilidad por evaluación. (Cf. Juan Noemí, Esperanza en busca de Inteligencia. Atisbos teológicos, Ed. Universidad Católica, de Chile, santiago, 2005, 117). Volveremos sobre este punto más adelante.

(25) Cf. Sergio Micco y Eduardo Saffirio, "Comunitarios: ni liberales ni conservadores", en Política \& Espíritu. Revista de pensamiento humanista cristiano, Santiago, 2005, 33-37.

(26) Eugenio Tironi con la colaboración de Tomás Ariztía y Francesca Faverio, El sueño chileno. Comunidad, familia y nación en el Bicentenario, Aguilar, Santiago, 2005, 26. 
sociedad, personas sin comunidad, son realidades parciales, incompletas, con las que difícilmente se puede fundar una vida en sociedad.

El desafío de nivel planetario para construir estructuras políticas y jurídicas que enmarquen el capitalismo desbocado no exime de las tareas políticas y culturales a nivel de los Estados (de modo que estos sigan siendo fuentes de reconocimiento y de justicia para sus ciudadanos) y al interior de estos de modo de reconocer, también jurídicamente, las tradiciones culturales que los forman. Estas últimas, a la vez que son el remedio al individualismo, son la fuente de lo que puede ser una ciudadanía multicultural de nivel supranacional (27).

Más allá de las virtudes o defectos que puede tener estas metáforas, completemos lo dicho sobre el ethos de la globalización (28). Son las tecnologías de la comunicación y la informática las que prestan el soporte tecnológico al mercado financiero internacional (29). Un uso especulativo del capital financiero que puede provocar crecimiento económico destruyendo los puestos de trabajo. "Así, la globalización, entendida como la supremacía del capitalismo financiero planetario, informacional, desregulado y competitivo, se realiza con una desigual capacidad para articular, por una parte, a los segmentos dinámicos de la sociedad internacionalmente integrados, al mismo tiempo que, por la otra, margina y desconecta a quienes son nacionalmente excluidos y carecen de poder de generar ingresos habilitantes para formar parte de la sociedad global" (30). Un proceso que escapa a la acción deliberada y potencialmente racional de los Estados y comunidades políticamente organizadas. Esta pérdida de poder por parte de las comunidades histórico-nacionales hace que, por un lado, esos procesos (particularmente los financieros, pero también los mediáticos y tecnológicos) adquieran un carácter de anonimato, invisibilidad, automatización y desregulación que los hace aparecer como cuasi naturales. Por otro, al

(27) “Or, à l'heure actuelle, une théorie de la justice distributive adéquate devrait tenir compte des injustices issues de phénomènes transnationaux, voire mondiaux, et envisager une structure politique, à même d'assurer la justice économique, qui dépasserait de loin les limites des États-nations actuels. Mais de telles structures politiques tendraient à première vue à s'approprier des prérogatives et des juridictions qui appartiendraient, selon la dimension culturelle de la théorie de W. Kymlicka, à des regroupements politiques plus limités. Ces deux aspects de sa théorie semblent donc tendre vers un fédéralisme complexe qui répartirait des compétences entre les instances supranationales et subnationales, et les États-nations. L'articulation de ce type de fédéralisme représente à l'heure actuelle l'une des tâches les plus urgentes de la philosophie politique ". (Daniel Weinstock, recensión a la trad. francesa del libro de Will Kymlicka, Les théories de la justice (Montréal, Boréal, 1999, 363 p.) en Politique et Sociétés, Vol. 20, no 1, 2001).

(28) Las descripciones que aquí hacemos han sido tomadas del trabajo de R. García, P. Mena, E. Silva, "Ethos nacional y mundo globalizado", investigación en curso por publicar. Descripciones que a su vez refieren a los trabajos de Manuel CASTELLS, Panorama de la era de la información en América Latina: ¿Es sostenible la globalización?, en Fernando Calderón (coordinador), ¿Es sostenible la globalización en América Latina?, Fondo de Cultura Económica, 2003, Volumen II.; Zygmunt BAUMAN, La globalización. Consecuencias Humanas, Fondo de Cultura Económica, México, 1999; Franz HINKELAMMERT, El nihilismo al desnudo. Los tiempos de la Globalización, LOM, 2001; Pierre BOURDIEU, Contrafuegos. Reflexiones para servir a la resistencia contra la invasión neoliberal, Anagrama, Barcelona, 1999; Martín HOPENHAYN, Ni apocalípticos ni integrados. Aventuras de la modernidad en América Latina, FCE, 1994.

(29) Manuel CASTELLS, Panorama de la era de la información en América Latina: ¿Es sostenible la globalización? Fernando Calderón (coordinador), ¿Es sostenible la globalización en América Latina?, Fondo de Cultura Económica, 2003, Volumen II, p.19.

(30) R.García, P. Mena, E. Silva, ob. cit. 
debilitarse los Estados y al sufrir la transformación de la que hemos sido testigos, de Estados nacional-populares a estados liberales, estos dejan de ser uno de los grandes proveedores de reconocimiento a las personas. La naturalización de los procesos propios de los subsistemas (económico-financiero, informativo-tecnológico, político-electoral, etc.) y la pérdida de reconocimiento y de vínculos, son dos efectos del impacto globalizador sobre los Estados nacionales y las comunidades históricas que los constituyen (31).

No es del todo extraño que estos cambios que expropian el poder de los Estados y los ciudadanos, no hacia una comunidad deliberativa internacional -que es una tarea ineludible- sino hacia el funcionamiento desregulado y no deliberativo de los subsistemas, viene acompañada de una actitud neoconservadora que los considera como "la mejor versión de lo posible", como un inevitable frente al que no caben alternativas sino la apología de la pura facticidad, del status quo de lo presente (32).

Por el contrario, Norbert Lechner, en un intento de "apropiación ciudadana de los cambios en marcha" sugiere dos tareas políticas: enfrentarse a la naturalización de los diversos subsistemas, reivindicando el poder de regular su funcionamiento y construir un discurso político que no renuncie a mediar entre las lógicas funcionales de los sistemas y la subjetividad de las personas (33). Como fruto de estas dos tareas "la sociedad amplía la libertad individual y colectiva" y genera aquel "sentido común" que permite compartir las vivencias personales (34). Solo así puede darse el reconocimiento capaz de vincular la calidad de los procesos de individuación a la calidad de los procesos de socialización.

\section{Una modernidad que reconociendo las tradiciones es revitalizada por ellas}

Hemos sostenido que la instalación del ethos de la globalización impacta no solo en las culturas tradicionales sino también al propio ideario moderno, creando un proceso de modernización sin modernidad. Los tres factores que en la actualidad marcan lo fundamental del fenómeno social y de la vida política, son cuestionamientos radicales de la propuesta moderna, a saber, la creciente despolitización de la vida civil, la mercantilización de las relaciones sociales y la deconstrucción de la subjetividad moderna.

Por ello sostenemos que el conflicto relevante ya no se da entre la modernidad y las tradiciones religiosas (el catolicismo entre ellas), sino entre un ideario moderno, democrático, emancipador, constructor moral de la sociedad y por ello abierto a las peculiaridades culturales y religiosas de los pueblos que lo adoptan versus procesos de modernización, subsistemas procedimentales, violentos, globa-

(31) Ibíd

(32) Una naturalización de los fenómenos históricos, que parece tentar a J.J. Brunner, Malestar en la sociedad chilena. ¿De qué exactamente estamos hablando? Estudios Públicos, No 72, 1998, $184-$ 186 y que podemos apreciar cuando Tony Blair sostiene que oponerse a la globalización es como “oponerse a que después del otoño venga el invierno". Lo propio de la historia es que podemos enfrentar de muchas maneras el invierno.

(33) Norbert LECHNER, Infome PNUD, 2004, p. 2.

(34) Cf. Ibíd. 
lizadores y dependientes de la mundialización de Occidente. En definitiva la tesis que propicia "la apropiación ciudadana de los cambios en marcha" (N. Lechner) y la que sugiere que hay "una variedad de trayectorias hacia la modernidad" (J. Larraín) son hermanas, porque estiman que la historicidad de los sujetos individuales y colectivos, las tradiciones peculiares a las que ellos pertenecen y de las que forman parte, son determinantes a la hora de asumir lo que se presenta con pretensiones de universalidad.

Más aún nuestra hipótesis sostiene que en este conflicto fundamental, por el que aspiramos a una apropiación ciudadana de los procesos desbocados de la globalización, a una modernización con modernidad, a una trayectoria latinoamericana a la modernidad, esta última no será posible sin el recurso a las tradiciones vivas del continente. Sospechamos que el liberalismo político y el neokantismo moral -frutos preciosos de la modernidad- parecen no tener la suficiente fuerza para contener la avasalladora marea de darwinismo social que acompaña al (neo) liberalismo económico. Nuestra tradición republicana no es capaz de compensar o equilibrar el nuevo ethos de la globalatinización (la mundialización de occidente) con su mercantilización, despolitización e individualismo. Dicho ethos amenaza con "la disolución de nuestras comunidades en sociedades sin atributos" (35). En tales sociedades los más perjudicados son los más pobres, pues al debilitamiento de las tradiciones, del tejido social y del marco institucional, es correlativo el rol hegemónico del capital, que ya ni siquiera reconoce sujetos individuales, sino solo poder de compra.

La tesis es que el liberalismo contractualista (que podemos llamar liberalismo I (36)) no tiene los recursos suficientes para enfrentar la mercantilización y despolitización de los actuales procesos en curso. El individualismo de la autorrealización no basta para construir la comunidad y la sociedad. El liberalismo I, "que acentuaría al máximo los derechos individuales y la neutralidad del Estado carece de proyecto moral propio -cultural o religioso- y de metas colectivas más allá de la libertad personal, la seguridad de los ciudadanos y su bienestar" (37). Ante la carencia de recursos que impidan la exclusión social y la disolución ética de nuestros pueblos, que acompaña el ethos de la globalatinización, se requiere un segundo tipo, el liberalismo II, que "concebiría un interés del Estado en la supervivencia y el florecimiento de formas nacionales, religiosas o culturales particulares, sin que ello obstara para la defensa de los derechos individuales" (38).

El reconocimiento de derecho no solo a los individuos, sino también a colectivos, es un asunto que se ha ido abriendo paso en el seno de la propia tradición

(35) Raúl González, s.j., XXI Encuentro del Equipo jesuita latinoamericano de reflexión filosófica, San Miguel, julio 2004.

(36) Liberalismo I y II son nombres que Michael Walzer da a los dos tipos de liberalismo que Charles Taylor ha descrito en su artículo "La politique de recconnaissance". El artículo y el comentario de Walter en Ch. Taylor, Multiculturalismo. Différence et démocratie, Aubier 1994.

(37) Resumen que Walzer hace de la primera variante de liberalismo propuesta por Taylor en ibíd., 131. Ver también la "Introducción" de Carlos Thiebaut a Ch. Taylor, La ética de la autenticidad, Paidos, 31-32.

(38) Resumen que Walzer hace de la segunda variante de liberalismo propuesta por Taylor en ibíd, 132. Ver también C. Thiebaut, ob. cit., 32. 
liberal. Después de la amplia reformulación que Rawls hiciera del liberalismo político, con una mejor inclusión de la justicia social en esta tradición, los planteamientos de los comunitaristas y luego de los republicanos han revitalizado la filosofía política. La cuestión debatida es si basta con conceder a los derechos individuales el valor primordial y exclusivo (39), o si es posible reconocer derechos colectivos a las diversas tradiciones culturales (40).

Un debate relevante para la situación latinoamericana poblada de tradiciones culturales que no son "fuentes olvidadas de la moral", sino reservas morales y de conciencia con plena vigencia y actualidad. Por ello, por la vigencia y actualidad, de diversas tradiciones, y entre ellas el cristianismo y el catolicismo latinoamericano, "beber del propio pozo" es muy distinto de "toda añoranza y cualquier intento de regreso a un viejo mundo perdido" (41). Ser nuevamente interpelado por la plenitud del lenguaje presente en nuestras tradiciones es muy diverso de cualquier "nostalgia de Atlántidas sumergidas" (42). Porque epocalmente ya hemos atravesado el desierto de la crítica, y la nuestra no puede ser sino una segunda ingenuidad, cualquier crítica a la modernidad desde, por ejemplo el catolicismo, y cualquier propuesta de construir en América Latina una "modernidad católica" pasa por el esfuerzo de realizar un "catolicismo moderno". Ello significa que el recurso al catolicismo como fuente moral en la construcción de la sociedad se hace desde la valoración y defensa de las ideas e instituciones que definen la modernidad (y no desde las filas de sus detractores): "la democracia, los derechos humanos y las libertades, los afanes de la tolerancia y de la igualdad" (43). Inversamente la asunción de estos valores de la modernidad no obliga a la neutralidad ética ni al silencio respecto de las propias convicciones; tampoco a la apostasía de la adscripción teísta y menos a la renuncia de la confesión católica.

(39) Cf. Alain Renaut, “ Les ressources du liberalisme politique " Propos recueillis par Nicolas Weill, Le Monde daté du vendredi 29 octobre 1999). Resulta interesante que no solo sean los comunitaristas y los multiculturalistas los que cuestionan esta exclusividad. El propio A. Renaut si bien admite que " le fait de dire que les identités culturelles ont, à travers les individus qui les choisissent, un droit égal à s'exprimer dans l'espace public modifierait beaucoup notre conception de la République ", no esta dispuesto a franquear un limite : " celle qui consisterait à admettre en quelque façon des " droits collectifs ". Une telle conception introduit en effet une concurrence avec les libertés individuelles, dont le dernier modèle connu - à savoir la concurrence entre liberté et justice, liberté individuelle et justice sociale - a eu des conséquences effroyables. Dans la position communautariste, je ne vois pas d'autre part le " cran d'arrêt " propre à empêcher les dérives théologico-politiques. "(Alain Renaut, ibíd.)

(40) El filósofo canadiense Will Kymlicka que figura entre los pensadores políticos más influyentes de los últimos diez años, defiende en sus principales obras "une position selon laquelle l'individualisme moral qui est à la base de la philosophie libérale peut justifier dans le contexte de sociétés multinationales l'octroi de droits collectifs aux groupes nationaux minoritaires "(Daniel Weinstock, recensión a la traducción francesa de la obra de Will Kymlicka, Les théories de la justice (Montréal, Boréal, 1999), en Politique et Sociétés, Vol. 20, no 1, 2001.

(41) Carlos Thiebaut, "Introducción. Recuperar la moral: la filosofía de Charles Taylor", en Ch. Taylor, Etica de la autenticidad, Paidós, Barcelona, 1994, 13.

(42) Paul Ricoeur formula así su propuesta programática al inicio de su giro hermenéutico: "No nos anima la nostalgía de Atlántidas sumergidas, sino la esperanza de una recreación del lenguaje; más allá del desierto de la crítica, queremos ser nuevamente interpelados" (Ricoeur, La Symbolique du mal, Paris, Aubier, 1960, 481).

(43) C. Thiebaut, ob. cit., 13. 
No se trata de elegir entre el liberalismo político y una hermenéutica de las tradiciones, ni de reemplazar una ética de lo justo por una de lo bueno (44), sino de "articular la herencia política del liberalismo, con toda su deducción y su atención a la idea de lo justo y de la imparcialidad, con las tradiciones culturales particulares y con las ideas de bien que esas tradiciones encarnan" (45).

Esta vasta tarea de articulación y mediación a nivel continental entre el humanismo laico y el humanismo cristiano, entre el liberalismo republicano y el catolicismo latinoamericano, pasa no solo por el reconocimiento y valoración de las respectivas tradiciones, sino también por el reconocimiento de las otras tradiciones que pueblan nuestro continente.

\section{INTERPRETAR LA SITUACIÓN LATINOAMERICANA: LA TRANSFOR- MACIÓN DE LAS TRADICIONES RELIGIOSAS}

Se pueden destacar cuatro grandes tendencias de la religión en América Latina: la diversificación del catolicismo, el desarrollo del protestantismo, la multiplicación de las alternativas religiosas y la presencia de la indiferencia (46). Al intentar ordenar el complejo panorama religioso latinoamericano en estos cuatro grupos hay que reconocer inmediatamente el aspecto quizás más característico de lo sucedido en las últimas décadas: el pluralismo, el entrecruzamiento, la difuminación, el sincretismo que atenta contra cualquier intento de tipología. La pérdida de la hegemonía del catolicismo -o mejor "la disminución progresiva de su hegemonía" (47) - significa no solo que el protestantismo pueda crecer y desarrollarse y que se abre espacio tanto a nuevos movimientos y expresiones religiosas como a la increencia, sino que el propio catolicismo se fragmenta en una pluralidad de alternativas. Con todo, aun perdiendo su hegemonía, fragmentado y en un lento descenso, el catolicismo sigue siendo de lejos la religión mayoritaria del continente: su $85 \%$ contrasta fuertemente con el casi $10 \%$ hasta ahora alcanzado por el crecimiento de los evangélicos y los escaso $2,5 \%$ que alcanzan respectivamente la indiferencia y los nuevos movimientos religiosos, a pesar de su enorme diversidad, y a veces desproporcionada atención (48).

(44) La reflexión filosófica de Paul Ricoeur es señera a este respecto, y son ejemplares sus esfuerzos de articulación entre la ilustración y el romanticismo, en su trabajo "Herméneutique et critique des idéologies" (Du texte a l'action, Seuil, Paris, 1986), entre el momento teleológico y deontológico de su pequeña ética (Soi-meme comme un autre, Seuil, Paris, 1990), entre liberales y comunitaristas en varios de los artículos dedicados a Rawl, a Taylor a Walzer (Le juste I y II, Seuil, Esprit, 1995 y 2000).

(45) C. Thiebaut, ob. cit., 32.

(46) Cristián Parker, "Introduction" a Les transformations du chap religieux en Amérique latine, Social Compass 45 (3), 1998, 323-333.

(47) C. Parker, art. cit, 324.

(48) Completaremos más adelante estos datos promedio, tomados de C. Parker, Otra Lógica en América Latina, FCE, Santiago, 1993, 241-250, con algunos otros guarismos respecto del catolicismo. 


\section{La pluralización del campo católico}

Lo nuevo es, lo hemos dicho y lo repetiremos muchas veces, el pluralismo de las expresiones religiosas, que se traduce en la pérdida del monopolio y la exclusividad del catolicismo, en que el pentecostalismo tenga carta de ciudadanía y en que afloren por doquier nuevas y variadísimas ofertas religiosas, incluidos aquellos que no se adscriben a ninguna. Pero será necesario reconocer desde la partida que el peso de estas cuatro tendencias es muy desigual, y que quizás, por esta misma desproporción numérica, lo más significativo sea el modo como este pluralismo afecta al interior del propio catolicismo. "En nuestro caso es cierto que, a diferencia de Europa, todavía podemos considerar a América Latina como un continente fundamentalmente cristiano y aún católico. Pero más cierto es que ya se rompió la homogeneidad de antaño, que ahora incluso el catolicismo se vive de maneras muy variadas, y más todavía, por supuesto, el cristianismo, y que además existe una gama muy extensa de formas religiosas. También la indiferencia -aunque no el ateísmose ha hecho socialmente significativa. Talvez sea todavía más decisivo el hecho de la distancia casi abismal entre las distintas formas de vivir el catolicismo, una distancia sin duda mayor que entre algunas de ellas y otras cristianas no católicas, e incluso talvez entre otras formas religiosas no cristianas" (49).

Karl Rahner sostiene que un asunto de fondo del Concilio es el fin de un único cristianismo, el europeo, y la apertura a una verdadera catolicidad. Si el Vaticano I reforzó el primado, señalando las condiciones de su infalibilidad, el Vaticano II insistió en la colegialidad y en el reconocimiento de las iglesias particulares. Si es cierto que debemos encontrar los modos de representar la unidad, de mantener la comunión, se trata de la unidad de los diversos, de la comunión de los distintos.

El catolicismo hoy, como el mundo, es plural. Se es católico de muchas maneras, aparentemente tantas como contextos de inculturación del Evangelio existen, tantas como situaciones culturales e iglesias particulares se den: hay un catolicismo europeo y un catolicismo norteamericano, un catolicismo africano y un catolicismo asiático. Nuestro mismo catolicismo latinoamericano es fruto de un mestizaje, de una mezcla o hibridación entre un catolicismo muy particular, el hispano lusitano del siglo XVI que fue impuesto o propuesto a nuestras culturas originarias, que sucesivamente lo rechazaron, recibieron, transformaron, asimilaron, adaptaron o apropiaron. De esa mezcla surge un catolicismo conservador en las elites y un catolicismo popular en la base, y de ambos surge un catolicismo que se renueva en la versión reformada-moderna o en la revolucionaria-liberadora (50).

(49) Pedro Trigo, "Fenomenología de las formas ambientales de religión en América Latina, en Duran, Scannone, Silva, Problemas de filosofía de la religión desde América Latina, Siglo del Hombre Editores, Bogotá, 2003, 39.

(50) Los cuatro tipos son descritos por Pedro Trigo en los años inmediatamente posteriores al Concilio. Casi 40 años después nos ofrece una nueva tipología que distingue ocho tipos de catolicismo. Cf. Pedro Trigo, "Fenomenología de las formas religiones ambientales en América Latina", en V. Durand, J.C. Scannone, E. Silva (comp.), Problemas de filosofía de la religión desde América Latina. De la experiencia a la reflexión, Siglo del Hombre, Bogotá, 2004, 37-121. 
El catolicismo, si bien ha bajado su adhesión en los últimos 50 años, sigue siendo la religión mayoritaria del continente (51). Pero la diferencia más significativa quizás no es numérica sino cualitativa. Este proceso de pluralización dice relación con otro proceso muy vinculado y que es recogido con acierto por un informe del Programa de Naciones Unidas para el Desarrollo (52): un proceso de individualización, que afecta el sentido de pertenencia y de adhesión, que está asociado a los procesos de modernización, y que puede derivar en el fenómeno de individualismo de la autorrealización al que aludimos en la primera parte. "Los cambios de las identidades y pertenencias sociales" se explican por la "subjetivación y desinstitucionalización de la experiencia religiosa": "en la medida en que la religión se subjetiva y privatiza, su regulación y expresión social e institucional pierde importancia" (53). Juan Noemi comentando el informe y la precisión de Pedro Güell de que estaríamos pasando de una "credibilidad por fusión o adhesión" a una "credibilidad por evaluación", nos dice: "en la primera el individuo al confiar e identificarse con una determinada institución se valida a sí mismo. En cambio, la 'credibilidad por evaluación' es individual, y, cada vez más, si se cree en una institución es por la experiencia que provoca y no por sí misma. De allí que el desafío de las iglesias, guste o no, se configura como oferta de sentido a personas evaluantes. Este cambio en el potencial creyente de adherente a evaluante configura un desplazamiento, no una negación, de la experiencia de trascendencia”. Esta experiencia de trascendencia -continúa el teólogo- "se configura en la experiencia consigo mismo y no más fuera, en las instituciones religiosas cuya fragilidad y contingencia se perciben con creciente evidencia. Al auge de la literatura de autoayuda y la atracción por una religiosidad new age es correlativo una creciente desafección por las instituciones religiosas, especialmente por la Iglesia Católica" (54).

El pluralismo afecta también a los esfuerzos realizados por la teología y el magisterio latinoamericano por comprender la situación del continente desde la fe. La tarea que nos dejó el Concilio hace 40 años de "auscultar los signos de los tiempos" ha sido diligentemente asumida por la Iglesia latinoamericana, que a la luz de ese esfuerzo se ha ido autocomprendiendo ella misma proponiendo proyectos eclesiales y teológicos de diverso signo. La riqueza plural del continente y los

(51) Las cifras muestran una lenta disminución desde el 92,3\% en 1900 a 88,7\% en 1980 y a la estimación de $85 \%$ en 2005. Un descenso que en los últimos 50 años es menos del 5\% en la mayoría de los países. La mayor parte de la población LA se concentra en los 15 países "más católicos" (en orden, México (95,9\%), Honduras, Colombia, Ecuador, Perú, El Salvador, Paraguay, Bolivia, Rep. Dominicana, Guadalupe, Venezuela, Argentina, Nicaragua, Haití (89,5\%)) donde el porcentaje de católicos alcanza el 92,9\%. En los países "relativamente católicos" (Brasil, Guatemala, Panamá, Costa Rica, Puerto Rico, Chile, Uruguay y Belice) el porcentaje de nocatólicos se eleva al 20\%. Algo muy diverso ocurre en los países "menos católicos", que totalizan solo 16 millones de habitantes, en el que el porcentaje de católicos no supera el 14\% (Guyana, Surinam, Cuba $(41,2 \%)$, Trinidad y Tobago, Jamaica y Barbados) (Los datos en C. Parker, ob. cit., 241-250).

(52) Cf. PNUD, Chile. Desarrollo humano en Chile 2002. Nosotros los chilenos: un desafío cultural (Informe del Programa de las Naciones Unidas para el Desarrollo), Santiago de Chile 2002).

(53) Cf. PNUD, op. cit. Los dos primeras líneas corresponden al título del capítulo 5 y al del último acápite de ese capítulo.

(54) Juan Noemi C., Esperanza en busca de Inteligencia. Atisbos teológicos, Ediciones Universidad Católica de Chile, Santiago, 2005, 117. 
cambios que hemos vivido a lo largo de estos años, bastarían para comprender por qué nos hemos visto confrontados -sea como partícipes vehementes o como espectadores impotentes- a posturas, perspectivas y visiones disímiles sobre la Iglesia y el continente. Interpretaciones no pocas veces en conflicto que los cristianos -seamos teólogos, filósofos, cientístas sociales, de la academia, de la jerarquía o de "a pie"debemos discernir e intentar mediar.

Subrayando esas diferencias el teólogo Joseph Comblin, hace ya algunos años, fue enfático en sostener que no es lo mismo comprender el continente desde la opción por los pobres, atendiendo a sus culturas destruidas y marginadas, que desde el impulso misionero de evangelización de la cultura en una continente que ve amenazado su identidad y sustrato católico por la adveniente civilización urbano industrial. Tampoco es lo mismo el imperativo de diálogo con la modernidad que propicia Vaticano II con la propuesta de una cultura cristiana como modo de acoger el llamado papal de una nueva evangelización de nuestros pueblos (55). Sin embargo, tanto el sentido común como la reflexión, saben que, aunque se trate de propuestas con concepciones eclesiales y políticas distintas y que dependen de proyectos teológicos diversos, siempre es posible un esfuerzo de mediación y de arbitraje de las interpretaciones en conflicto. No estamos obligados a contraponer como adversarios y enemigos entre sí al Concilio Vaticano II y su preocupación por el mundo moderno, a Medellín y la teología de la liberación con su opción por los pobres, a Evangelli Nuntiandi y Puebla con sus propuestas de evangelización de la cultura y su valoración de la religiosidad popular y del sustrato católico, y a Juan Pablo II y Santo Domingo con sus proyectos de nueva evangelización y de nueva cultura cristiana. Reconocer que en las raíces culturales del continente el catolicismo ha tenido una influencia decisiva no es contradictorio con observar los procesos de modernización en curso y efectuar el necesario discernimiento para asumir los valores de la modernidad en la inculturación del Evangelio. Todo ello, lejos de ser un impedimento para un compromiso teológico y eclesial desde y para los pobres, son elementos imprescindibles a considerar para que dicha opción tenga efectividad histórica y no se agote en un voluntarismo exhortativo y de buenas intenciones.

La preocupación por la suerte de los pobres en nuestras modernidades periféricas que intentan incorporarse en condiciones de desventaja al proceso de globalización del capital, nos exige poner en referencia al catolicismo latinoamericano no solo con el proceso de modernidad en curso, sino también con las transformaciones que vienen experimentando las tradiciones, religiosas y seculares que enriquecen el continente.

El sociólogo de la religión Cristián Parker resume bien estas transformaciones al señalar que una de las tendencias de la religión en América Latina es aquella de la diversificación del catolicismo, que llama la "fragmentación del campo católico" (56), en medio de un "abanico que se abre" (57). Volveremos en el último apartado

(55) Cf. J. Comblin, "Posturas teológicas sobre la cultura latinoamericana", en Teología y Cultura, STCh, Paulinas, Santiago, 1993.

(56) C. Parker, Otra lógica en América latina, ob. cit., capítulo.6.

(57) C. Parker, ibíd., capítulo 7). La abertura del abanico consiste en "la pluralización de alternativas religiosas" que se expresa en el florecimiento de iglesias evangélicas, en el incremento de Nuevos Movimientos Religiosos y en la difusión de los diversos cultos afroamericanos en algunos países del continente (Caribe y Brasil, pero también Uruguay y Argentina). 
al catolicismo completando esta imagen de pluralidad con una de comunión al enunciar los aportes que el conjunto de sus variantes está llamado a ofrecer. Nos asomamos ahora a dos aspectos de este abanico que se abre en el crecimiento evangélico y en la emergencia de nuevos movimientos religiosos.

\section{El crecimiento del pentecostalismo}

Hasta el siglo XIX el catolicismo es absolutamente mayoritario. El liberalismo y el protestantismo corresponden a grupos muy minoritarios y de elite. Las iglesias históricas protestantes son "de trasplantes" para mantener la fe de los inmigrantes anglosajones. Pero en este siglo junto con quebrarse el orden oligárquico, se rompe también el monopolio simbólico del catolicismo sobre las clases populares. Además de la presencia de anarquistas y socialistas en las masas obreras, entra en escena diversos grupos pentecostales que serán capaces de arraigarse en los medios populares (58).

A comienzos de siglo predicadores bautistas y metodistas, que suscitan un reavivamiento espiritual-pentecostal, son expulsados de sus respectivas iglesias, y dan origen así en Brasil a las Assembleias de Deus y en Chile a la Iglesia Metodista Pentecostal, dos de las principales iglesias pentecostales autóctonas de América Latina (59). El modo de crecimiento en los distintos países es muy variado, en algunos se desarrolla en zonas rurales y de mayor composición indígena, en la mayoría en zonas periféricas urbanas, en todos es eminentemente de carácter popular. Se estima que el $10 \%$ de la población latinoamericana es protestante (45 millones) y de ellos 30 a 35 millones, vale decir más de las dos terceras partes, son pentecostales. En algunos países son menos del 5\% (Colombia, Venezuela, Perú, México), en Chile y Brasil la cifra se eleva por sobre el $15 \%$ con alto crecimiento desde los años 50 (60). En partes de América Central se expande desde los años 70 y en Guatemala se estima en más de un $20 \%$. Teniendo en cuenta las diferencias entre los países es posible sostener que protestantes y evangélicos en América Latina son fundamentalmente pentecostales (61).

Las razones para explicar este crecimiento han sido variadísimas. No pocos analistas católicos las evalúan desde la peyorativa categoría de sectas. La teoría de la conspiración es útil en este marco: las sectas crecen gracias a las motivaciones políticas del dinero americano. En este tipo de explicaciones, y otras afines, se "retrata a la gente como víctima de métodos propagandísticos o moneda extranjera. Incapaces de adaptar una religión a sus propias necesidades, ellos deberían ser

(58) Cf. C. Parker, Otra lógica en América latina, ob. cit., 250-251.

(59) Ibíd.

(60) La minoría protestante en Chile que era de 5,6\% según el censo de 1960 y de 6,06 según el censo de 1970 (con fuerte concentración en Concepción $(13,9 \%)$ y Arauco $(15,6 \%)$ y tasas inferiores al $3 \%$ en Coquimbo, Colchagua y Aysen), llega cerca del $15 \%$ en la actualidad.

(61) "El crecimiento del protestantismo en Chile es atribuible casi en su totalidad al pentecostalismo, que agrupa a la gran mayoría de los protestantes chilenos" (Manuel Ossa, "Trabajo y religión en el Pentecostalismo", en O. Mella y P. Frías (ed.), Religiosidad popular, trabajo y comunidades de base, Primus, Santiago, 1991,45). Más del $80 \%$ de los protestantes en Chile, cerca de los $70 \%$ en Brasil, $30 \%$ en los países andinos 
protegidos por la Iglesia madre o el estado paternalista. 'Sectas' solo crecen debido a patologías, religiosas (las deficiencias de la pastoral católica) o sociales (pobreza, anomia). Ellas nunca parecen ser signos de salud del cuerpo social" (62).

Pero la teoría de la "invasión de las sectas" parece construir sus datos. Además de observar las muchas conexiones extranjeras del protestantismo hay que preguntarse cuán importantes son. En algunos países (Centroamérica) el Protestantismo es más susceptible de influencia extranjera que en otros (Brasil, Chile). "Pero en personal y dinero, el catolicismo y el protestantismo histórico son más extranjeros. Sin gran recurso y organización el pentecostalismo no crea relaciones de dependencia" (63).

Otra versión de la teoría patológica vincula el crecimiento a la represión política. Pero los datos disponibles no la avalan (64). A menudo también se vincula el crecimiento con crisis económicas. "El sistema capitalista actúa como detonante de situaciones de explotación y marginación que incrementan la angustia y la incertidumbre frente a la cual -entre los indígenas y los grupos urbano-marginales- el pentecostalismo con su mensaje de reavivamiento religioso confiere sentido y esperanza alimentando de afecto, espíritu, fraternidad y euforia religiosa la monótona vida del oprimido por el sistema" (65). La función alienante de algunas formas pentecostales ha sido denunciada desde hace tiempo por Lalive en El refugio de las masas (1968). Otros sin embargo aprecian, que más que un refugio, la conversión se transforma en un motor que posibilita mejores condiciones de vida. La "salud y bendición del Evangelio" ofrece una religión de resultados.

Si las explicaciones son muy unilaterales dejan fuera aspectos que se vuelven muy paradójicos. La religión es ambivalente y ofrece diferentes cosas a diferente gente. Se deben tomar en cuenta no solo los factores políticos y económicos sino también los sociales, culturales, étnicos y religiosos. Consideraciones de nivel macro (características sociales que favorecen la conversión) junto con las del nivel micro (porque solo algunas personas con estas características se convierten) permitirán comprender no solo por qué el pentecostalismo crece, sino también por qué no crece más, y por qué algunos tipos crecen más que otros (66).

Razones que tienen que ver con el mismo clima cultural han sido aducidas. El crecimiento refleja la expansión del pluralismo y la autonomía personal. Se dilata el sentido de bloque cultural y de unidad tradicional: el catolicismo fue importante en esta unidad y su erosión tiene estas regionales repercusiones. El modelo pluralista gana terreno en un contexto favorable socialmente (la urbanización rompe la vieja unidad), jurídicamente (hay facilidades legales para fundar grupos religiosos) y culturalmente (es aceptada la posibilidad de la conversión) (67).

(62) Paul Freston, Pentecostalism in Latin America: Characteristics and Controversies, Social Compass 45(3), 1998, 344-345.

(63) Ibíd., 345.

(64) Ibíd., 346-347.

(65) C. Parker., ob. cit., 253.

(66) Cf., P. Freston, art. cit., 347-348.

(67) Cf. Ibíd., 339. 
El pentecostalismo tiene como referencia a diversas tradiciones cristianas (68), "que tienen en común con el pentecostalismo la acentuación de la conversión personal e interior, la importancia atribuida al don del Espíritu Santo y una cierta expectativa escatológica" (69). Lo fundamental es el Evangelio, la conversión y las consecuencias que trae para la vida de los individuos: conversión moral y lograr un buen pasar en esta vida, e.d., salud y un relativo bienestar. Hay reciprocidad entre ser fiel a Dios y este buen pasar que se espera. "Así pues, a Dios se lo busca no solo por sí mismo, sino porque su cercanía es también un ámbito de poder, de amparo o refugio y una fuente de salud. En la religiosidad pentecostal se vuelven a encontrar, pues, algunos temas clásicos de la historia de las religiones y de la religiosidad popular" (70). "Según esto, la religiosidad pentecostal tendría rasgos en común con la religiosidad popular católica y podría discutirse en función de algunos de los marcos de interpretación que de esta se han dado" (71).

También resulta muy fecunda la comparación del pentecostalismo con el catolicismo progresista. El primero sería "una opción de los pobres" en referencia a la menos exitosa "opción por los pobres" del catolicismo (72). Cecilia Mariz habla de las similitudes y diferencias entre las Comunidades Eclesiales de Base (CEBs) y el Pentecostalismo. "Ambos rompen con el fatalismo. Ambos desarrollan la dignidad y la capacidad de expresarse por sí mismo. Ambos representan racionalización y motivación religiosas para tratar con pobreza. En el largo plazo, ellas tienen consecuencias similares, a pesar de sus discursos contrastantes. Sin embargo, las CEBs no emergen espontáneamente desde los pobres. Ellas atraen gente que siempre tiene un estilo de vida ordenado; pentecostalismo da un estilo de vida ordenado a quienes no lo tienen. Mientras el pentecostalismo cambia los valores de la religión popular, las CEBs cambian su cognición. Entonces los pentecostales lo hacer mejor pues sus asumciones cognitivas son más cercanas a la cultura popular, y sus líderes son de su mismo origen" (73).

Estos vínculos tanto con la religiosidad popular como con el catolicismo progresista han hecho cuestionar la pertinencia de seguir considerando el pentecostalismo latinoamericano como una religión "protestante". El protestantismo comienza en América Latina con la cultura del liberalismo radical, inculcando los valores democráticos. Pero hoy el pentecostalismo involucra elementos de la cultura del pueblo, católicos, sincréticos, corporativistas y pasivos políticamente. Frente al carácter minoritario y elitista del protestantismo histórico, "el pentecostalismo es la primera

(68) "Como la del siglo XVI, la pietista de los siglos XVII y XVIII (Spenner, Francke, Zinsendorf), el movimiento de santidad de Wesley en el siglo XVIII, los movimientos de santidad pentecostales en el siglo XIX en los Estados Unidos" (Manuel Ossa, "Trabajo y religión en el Pentecostalismo", en O. Mella y P. Frías (ed.), Religiosidad popular, trabajo y comunidades de base, Primus, Santiago, 1991, 45).

(69) Ibíd., 45.

(70) Ibíd., 48-49.

(71) Ibíd., 49

(72) Cf. P. Freston, art.cit., 338.

(73) Cecilia Mariz, "Religion and Coping with Poverty in Brazil", PhD thesis Boston University, 1989. El resumen es presentado por P. Freston, que también sintetiza la comparación que realiza J. Burdick, Looking for God in Brazil, Berkeley, University California Press, 1993, en art. cit., 349. 
religión de masas autónoma en latinoamerica" (74). En réplica a la aplicación que, de las conocidas tesis de Weber sobre los efectos económicos del protestantismo, hace Peter Berger ("una sólida burguesía, con virtudes que conducen al desarrollo de un capitalismo democrático" (75)), podemos decir que "el pentecostalismo latinoamericano no tiene la clásica ética del trabajo protestante, y opera en un contexto económico diferente. Es escasa la evidencia de movilidad social, y aún más escasa la de efectos macroeconómicos" (76).

\section{Multiplicación de las alternativas religiosas}

La literatura sobre los nuevos movimientos religiosos (NMR) es abundante (77). Se trata de un fenómeno global que no solo afecta a Latinoamérica (78), y expresa con suma claridad el rasgo fundamental que venimos destacando: la pluralidad, la variedad, la heterogeneidad, la profusión de formas religiosas que se distancian y distinguen de las religiones e Iglesias tradicionales.

Intentar una clasificación no es fácil y obviamente dependerá del criterio adoptado. Así, por ejemplo, M. Yinger (79) considerando la relación que guardan con el mundo, "distingue entre sectas agresivas o revolucionarias que rechazan el mundo, gnósticas o de aceptación del mundo, e introvertidas que lo evitan" (80). Por su parte B. Wilson (81) atendiendo a la doctrina de salvación como criterio, distingue entre sectas conversionistas, revolucionistas, introversionistas y manipulacionistas (82).

Presentaremos aquí el ordenamiento que hace J. Marín Velasco considerando las religiones o tradiciones espirituales de las que proceden. Un primer grupo son los NMR surgidos en las religiones autóctonas de pueblos del tercer mundo al entrar

(74) P. Freston, art.cit., 352.

(75) Citado por P. Freston, art. cit., 352

(76) Ibíd., 353.

(77) Solo por mencionar un par, J. Gordon Meltor, en The Encyclopedia of American Religions, Book Tower, Detroit 1989 agrupa las 1588 religiones americanas en familias que van desde las religiones históricas y las iglesias establecidas a los grupos y movimientos espirituales más diversos. Por su parte el Hanbuch Religiöse Gmeinschaften, G.Mohn, 1985, "agrupa estas comunidades religiosas en seis apartados: iglesias libres, comunidades especiales, sectas, cosmovisiones, movimientos esotéricos, neognósticos, religiones misioneras de oriente y nuevas religiones (religiones de la juventud), y cosmovisiones religioso-filosóficas" (J. Martín Velasco, El malestar religioso de nuestra cultura, Paulinas, Madrid, 1993, 58).

(78) Un ambicioso proyecto de investigación al respecto ha sido realizado por la F.I.U.C. durante cerca de siete años incluyendo la organización de seminarios en varios continentes (Quito 1992, Kinshasa 1992, Manila 1993). En una de las publicaciones que recoge parte de los resultados, M. Fuss (ed.), Rethinking New Religious Movement, Gregorian University, Rome 1998, 792 pág., la primera parte se ocupa de artículos que refieren a "The Global Phenomenon of New Religious Movement" y la segunda a los que abordan la especificidad del fenómeno en Africa, norteamérica, latinoamérica, Asia, Europa y Oceanía.

(79) The Scientific Study of Religion, Macmillan, Londres, 1970.

(80) J. Martín Velasco, El malestar religioso de nuestra cultura, 57.

(81) Sociología de las Sectas Religiosas, Guadarrama, Madrid, 1970.

(82) Cf. J. Martín Velasco, ob. cit., 58. Basándose en otra tipología de Wilson que agrega cuatro tipos más (taumatúrgicos, reformistas, utópicos y mixtos), J. L. Sánchez Nogales, Religión, religiosidad alternativa y sectas, Ed. CCS, Madrid, 2000, 139-151, llega a diez tipos al agregar por su parte la nueva religiosidad (del new age) y las sectas satánicas. 
en contacto con la cultura y religión de los colonizadores, sobre todo el cristianismo y el Islam.

Un segundo grupo son los movimientos de renovación surgidos al interior de las grandes religiones a raíz del contacto con la modernidad. Por ejemplo en el interior del hinduismo hay movimientos que intentan responder a la crítica de la conciencia moderna y hay otros que surgen o se extienden en occidente, que se ve seducido por esta especie de llamada del oriente. "Comparten el cultivo de la interioridad, el recurso a la experiencia, la utilización de métodos de concentración y relajación, la tendencia a pensar en la supervivencia con el esquema de la reencarnación, una representación ordinariamente monista de la divinidad, la adscripción a la no violencia, la utilización de regímenes vegetarianos de alimentación, etc." (83). Fenómenos similares ocurren con el Budismo y con los movimientos surgidos en el Japón, que han exportado diversas formas de meditación, y al interior del Islam, dando origen a dos religiones que se han independizado de la matriz musulmana: el bad o badismo y el bahaísmo que se proclama como religión universal.

Párrafo aparte merecen los múltiples movimientos de origen cristiano, en los que es posible distinguir dos momentos. En el primero se ubican los movimientos desgajados de las Iglesias de la reforma en Europa y particularmente en Norteamérica: a ellos pertenecen la familia pietista-metodista y la familia pentecostal a la que nos hemos referido. Pero también "las Free Churches europeas y americanas: menonitas y cuáqueros; la familia bautista; la adventista (...), los mormones; Christian science; los Testigos de Jehová, etc." (84).

En un segundo momento se han originado otra serie de grupos religiosos de origen cristiano, a los que cabe aplicar la noción de NMR: "movimientos como Jesus People, los Niños de Dios o familia del amor, la Iglesia de la unificación del cristianismo (Moon)" (85). Grupos en los que la distancia con las fuentes cristianas es mayor y la cercanía con la nueva cultura los hace tender al sincretismo. Grupos en los que los que se acrecientan los rasgos sectarios "conciencia de ser los puros y elegidos, seguridad y dogmatismo en sus convicciones, rechazo de todo lo externo al

(83) J. Martín Velasco, ob. cit., 60.

(84) Ibíd., 62. Con frecuencia se ha dado a estos movimientos el nombre de secta, siguiendo la elaboración teórica de la sociología de la religión de M. Weber ("secta es aquella comunidad que, por su esencia, renuncia sucesivamente a la universalidad y se siente pura") y E. Troeltsch ("grupo pequeño, cerrado, que nace y crece como reacción ante un grupo, o grupos, religioso, mayor y organizado"; ambas definiciones citadas por J. L. Sánchez, ob. cit., 31). Lamentablemente el término ha ido adquiriendo connotaciones muy peyorativas asociándose a segregación, pequeñez, excesos, fanatismos que es injusto aplicar a alguna de las iglesias recién mencionadas. Con todo el término, que algunos prefieren a los de "denominación" o "culto, parece ubicarse entre la categoría de Iglesia y el más reciente de NMR. J. Martín Velasco explicita los rasgos que nos permiten distinguir una secta de una Iglesia: "La secta se distingue, en contraposición a los rasgos de la Iglesia, por significar una unidad sociológica, disidente de un grupo mayor, compuesta por un número relativamente pequeño de adeptos voluntarios, pertenecientes generalmente a las capas más desfavorecidas de la sociedad, con un grado grande de dependecia de un líder carismático, lazos interpersonales muy estrechos entre sus miembros dentro de un plano de igualdad, escasa importacia de las doctrinas como medio de identificación y de definición de pertenencia y un culto en el que predomina lo emocional y que concede gran importancia al fervor afectivo. Generalmente... conceden escaso interés al mundo... y preparan a sus miembros para un final próximo en el que será posible una felicidad reservada para ellos" (Martín Velasco, ob. cit., 62)

(85) Ibíd., 64. 
propio grupo y gran espíritu de cuerpo (...) utilización fundamentalista de la Escritura confundida con una revelación literal de Dios al propio grupo" (86).

Por último, un tercer grupo de movimientos son los que proceden de raíces filosófico-religiosas emparentadas con las corrientes gnósticas, esotéricas y ocultistas. Sea con los recursos de la ciencia, de la psicología o de los procedimientos curativos se busca dilatar la conciencia, acrecentar el psiquismo y el potencial de sus adeptos. "Entre ellos se cuentan movimientos como Nueva Acrópolis, la Gnosis de Carf, la Iglesia de la cienciología, las sociedades teosóficas, los rosacrucianos, etc." (87).

La distinción en estos tres grandes grupos dependiendo si los NMR surgen de raíces autóctonas, de las grandes religiones o de raíces filosófico-religioso, no impide las mezclas y las mutuas influencias. Se trata de un fenómeno global cuyas peculiaridades en América Latina no es fácil discernir. Lo más distintivo tiene que ver con la influencia y sintonía que pueden tener con nuestras religiones indígenas y con los cultos afroamericanos -asunto que merecería un tratamiento específico que aquí no podemos hacer $-\mathrm{y}$ con los vínculos que pueden establecer con elementos y raíces cristianas que sí se encuentran en el continente. Pero, en general, se trata de movimientos nuevos y bastante globalizados.

Este carácter global se aprecia también en la influencia que tienen en el continente los movimientos surgidos en Norteamérica. Al respecto J.L. Sánchez distingue los movimientos surgidos en lo que el llama el "Gran Despertar" americano de los siglos XVIII y XIX de los que se originan en el "Nuevo Despertar" vinculado a la new age que asoma en California en la década del 60. De ese primer despertar vienen nuestros protestantes y el pentecostalismo pues como sabemos tienen su origen en ese metodismo-pietista que contribuyó a la creación de Norteamérica. De allí surgirá el fundamentalismo americano y también movimientos religiosos alternativos que han llegado nuestro continente como mormones, adventistas y testigos de Jehová. En cambio el Nuevo Despertar se acerca bastante más a los movimientos que describíamos con raíces filosófico-religiosas, pues se trata más de una espiritualidad que de una religión, en la que se mezclan elementos de "la religión judeocristiana, la secularización cientista, la sombra de la religión (gnosis, ocultismo y herejías) y las religiones orientales" (88).

El carácter de novedad que poseen los NMR hace menos predecibles qué cambios pueden sufrir en el futuro. El hecho que sus miembros se hayan unido más bien que nacido dentro del movimiento, el que el movimiento comienza con una particular composición con relativamente pocas personas dependientes (ancianos o niños), el que los miembros se volverán más viejos y niños nacerán dentro de él y el que los líderes fundadores, quienes poseen una autoridad carismática, morirán, todos estos factores y otros relacionados con ellos hace que lo que son los movimientos hoy pueda ser muy distinto a lo que sean mañana (89).

Su sincretismo difuso, novedad y universalidad son rasgos de estos movimientos que hacen todavía más incierto predecir su futuro y desarrollo. No es claro si

(86) Ibíd., 63.

(87) Ibíd., 64.

(88) J.L. Sanchez, ob. cit., 85.

(89) Cf. Eileen Barker, "Changes in New Religious Movements", en M. Fuss, ob. cit., 9 
lograrán salir del actual carácter minoritario que poseen hoy en América Latina y si su impacto mayor lo alcanzarán por la influencia ambiental que logren tener en las diversas versiones del cristianismo latinoamericano.

Podemos resumir esta panorámica descriptiva de las cuatro transformaciones que en el campo religioso latinoamericano nos parecen lo más significativo de los últimos años: pluralización del catolicismo (que con todo sigue siendo mayoritario), crecimiento y consolidación del pentecostalismo, emergencia de NMR y las vicisitudes de la increencia y el indeferentismo. Cuatro fenómenos muy diversos en términos cuantitativos: el 10\% de pentecostales es muy diverso del $80 \%$ de latinoamericanos que se declaran católicos y del cuasi 2,5\% que participan en los tan mentados NMR. Los porcentajes de increencia son todavía bajos, pero significativos en la elite y los mass media. Son diversos también, y sorprendentes en términos cualitativos: nuestros pentecostales tienen menos que ver con las iglesias protestantes europeas que con los rasgos de la religiosidad popular (de matriz católica) que permea sus prácticas y el ethos popular en el que se encuentran; los NMR, si bien son minoritarios en cuanto a sus militantes, lo son menos en cuanto a su radio de influencia particularmente en el mundo católico y también en el mundo de la indiferencia, que afectada por el proceso de secularización observa cómo hoy se pone de moda lo religioso.

Obviamente estas transformaciones de nuestro ethos religioso seguirá recibiendo el impacto del ethos de la globalización y de los fenómenos de despliegue descontrolado del capitalismo financiero y del individualismo de la autorrealización, que subrayamos más arriba. Frente a la conjunción de todos estos signos del tiempo (moderno) y de la situación (continental), nos interesa terminar con algunas notas que retoman nuestro empeño de articulación entre la tradición moderna, en particular la liberal republicana, y las tradiciones religiosas, en particular el catolicismo latinoamericano.

\section{SEÑALES DE RUTA Y PISTAS PROVISORIAS PARA MODERNOS Y CA- TÓLICOS}

\section{Pluralismo y tradiciones con ideales de excelencia}

Nuestros análisis han dejado en evidencia la importancia que tiene el fenómeno de la "pluralización". La salida del eurocentrismo, el reconocimiento de otras culturas, la actual sensibilidad posmoderna, nos han hecho diferenciar, incluso en el fenómeno de la modernidad, que suele presentarse como homogéneo y universal, "sucesivas" modernidades, modernidades "entrecruzadas", "segundas" modernidades y a preguntarnos por nuestra propia trayectoria hacia ella. Con más claridad aún hemos podido apreciar que lo religioso en América Latina está sometido a un proceso de pluralización. Nuevos movimientos religiosos emergen y nos afectan más que por la cantidad de sus fieles -que son escasos- por la difusa influencia ambiental que permea al resto de las tradiciones religiosas. El pentecostalismo crece y se convierte en una alternativa, que si bien todavía es minoritaria logra quitar la hegemonía absoluta al catolicismo. Hegemonía que ya era cuestionada desde algunas de 
las elites más secularizadas, que propician la increencia, el agnosticismo o la simple indiferencia religiosa. Hemos insistido, sin embargo, que es sobre todo en el catolicismo mismo que apreciamos este proceso de fragmentación y diversificación.

La pluralización es un hecho, y como hecho podemos decir que nuestro continente es más plural que antes. Podemos decir también que es menos plural que otros continentes. El pluralismo es una magnitud que admite distintos grados y da cuenta de sociedades más o menos plurales. Frente a este dato, a esta situación de hecho, la actitud ética y cívica más acorde es la tolerancia. Respetar la libertad del otro y reconocer su derecho a que piense y actúe de otra manera, requiere de nosotros la tolerancia como actitud y virtud. El individualismo reinante confunde la legítima promoción de esta actitud con una promoción de la pluralidad, que en el límite pareciera desear que hubieran tantas posiciones como sujetos. Posiciones que además habría que considerar como igualmente válidas y que exigen a quienes las detentan el sacrificio de mantenerlas en el ámbito privado y al Estado una postura neutral -un abstencionismo valórico- respecto de ellas. Por el contrario, cualquier promoción de identidades colectivas o de reconocimiento de vínculos comunes le parece un atentado a la pluralidad. Confundir un hecho con un ideal, es distinto de estimar que pueden haber niveles más o menos óptimos en esta magnitud en una sociedad dada, pues muy poco pluralismo impide la libertad y demasiado impide la convivencia. Podemos decir algo análogo de los niveles de pluralismo y diversidad que se dan al interior de una tradición religiosa, como por ejemplo en las distintas versiones de catolicismo latinoamericano. Muy poco impide la libertad y la riqueza de distintos carismas que enriquecen el cuerpo, demasiado pluralismo rompe con la identidad y la pertenencia a una misma tradición o religión. Cada tradición tiene el derecho de establecer esos límites y estimar que tal posición se aleja del canon y ha incurrido en la herejía. En el caso de la sociedad el pluralismo tiene uno de sus límites en aquello que no se puede tolerar en un contexto determinado. Lo intolerable puede ser sancionado jurídicamente o éticamente. Son mínimos exigibles. Pero existe también en una sociedad lo deseable, lo que se propone como ideal.

Es abstracta la separación entre mínimos y máximos, pues más bien se trata de un continuo. Siempre en toda sociedad hay unos mínimos exigibles junto con modelos de excelencia. Los liberales quieren llevar los límites hacia abajo, de modo que exista el máximo de libertad y un mínimo de exigencias comunes. Los conservadores quisieran el máximo de mínimos protegidos. Más sensibles los primeros al "problema de la legitimidad", rechazarán el que un grupo imponga su propia visión del bien a los demás. Más sensibles los segundos al "problema de la verdad" lucharan porque sus ideas particulares de bien encuentren un espacio en lo público (90). Estimamos que es difícil pero posible que las tradiciones renuncien a la fuerza y a la coacción para imponer sus ideas, que cultiven la virtud de la tolerancia con los otros grupos y que en definitiva sean capaces de convivir en el espacio democrático. Lo que nos parece irreal es pretender que las tradiciones no tengan concepciones del bien y propuestas respecto del bien común. Las tienen las iglesias más conservado-

(90) Cf. Sebastián Kaufmann, "Liberales y conservadores: Algunas claves para entender el debate", Mensaje, mayo 2005 
ras o las más revolucionarias, los partidos políticos de uno y otro signo, los ecologistas y la propia tradición liberal.

Las distintas tradiciones que conforman una sociedad, incluidas las religiosas tienen propuestas de sentido y de felicidad para esa sociedad. El asunto no es dirimir en abstracto si mi tradición religiosa, por ejemplo el pentecostalismo, es inferior o superior a la cultura hindú, o si tiene más o menos derechos en abstracto de existir; el asunto es que el pentecostalismo tiene de hecho una relación distinta con la realidad latinoamericana que la que tiene el hinduismo. Hay pentecostales en América Latina que socializan a sus miembros, les proponen códigos éticos y religiosos, los proveen de ideales de excelencia, y aspiran a que todo ello pueda ser vivido por el resto de la sociedad.

No es sostener una tesis de cristiandad o recaer en una teocracia el pretender que una comunidad cristiana o religiosa quiera preservar su identidad de cara a sus miembros y plasmar sus valores en el todo social. Pero si lleva a cabo estas tareas sin respetar la libertad y la conciencia de sus fieles y procura prevalecer jurídicamente o políticamente sobre la sociedad saltándose sus normas, se quedará sin adeptos y recibirá las sanciones de la comunidad política (91).

El equívoco es suponer que solo es sujeto de derechos el individuo. Pero si el sujeto también puede ser la comunidad, ella tiene derecho a reproducirse, a trasmitir sus tradiciones, a socializar a sus miembros, a proponer al conjunto de la sociedad sus concepciones del bien. Será necesario seguir buscando, en un debate que como lo reseñamos está todavía abierto, las formas de otorgar reconocimiento a las diferentes culturas que habitan al interior de las democracias occidentales y a las que no hacen parte de la tradición occidental. Por lo menos es necesario sospechar de una de las trampas de la modernidad abstracta, de la supuesta modernidad acultural que denuncia Charles Taylor (92), que no se reconoce como una cultura más sino como un universal al que supuestamente todos debemos encaminarnos y se adjudica el papel de árbitro supuestamente neutral.

\section{Una hermenéutica de las tradiciones seculares}

Parece entonces muy relevante la pregunta por las propuestas de sentido y modelos de excelencia que las distintas tradiciones e interlocutores reales del continente están proponiendo. En el apartado anterior identificábamos las tradiciones religiosas, reconociendo el desigual peso que tienen los NMR, el pentecostalismo y el catolicismo en sus variadas versiones. Conviene ahora identificar, aunque solo sea mencionándolas, las tradiciones seculares que gozan de existencia real en el continente. Un rápido catastro, que no pretende ser exhaustivo sino meramente indicativo, nos permite reconocer:

- $\quad$ el civismo republicano vinculado a los mitos fundacionales de nuestras naciones

- el positivismo ilustrado, científico y anticlerical, muy presente en el siglo XIX y comienzos del XX

(91) Cf. Jorge Costadoat, "Católicos en democracia”, Mensaje, septiembre 2005, 15-17. 
- distintas tradiciones de carácter más romántico (como el marxismo latinoaméricano, el indigenismo y el ecologismo)

- el feminismo, la lucha por el reconocimiento de los derechos de la mujer y ahora de los géneros y las minorías sexuales

- la marea difusa del amplio fenómeno del new age, al que ya nos hemos referido, pues es una de las fuentes de los cambios religiosos

- la deconstrucción posmoderna presente en algunos restringidos espacios de la universidad y el arte, y

- la lógica de socialización del capitalismo tardío con el (neo) liberalismo como ideología, con los mercados financieros y los medios de comunicación como soporte, al que nos hemos referido ampliamente.

Se trata de tradiciones, que como las religiosas, poseen distinto peso cualitativo y cuantitativo en América Latina, con influencias variables a lo largo de nuestra historia y con una presencia actual disímil. Tradiciones que poseen un ideario determinado, que desean captar adherentes, socializarlos en sus principios y que les interesa que sus propuestas contribuyan a la construcción de la sociedad. Tradiciones en diálogo y conflicto unas con otras y con paredes más o menos porosas que permiten que sus adeptos participen en más de una tradición, o que adopten o compartan algunos puntos de vista de la otra.

Todas ellas, cual más cual menos, han pasado por el cedazo de la modernidad. En todas ellas, tanto las religiosas como las seculares, sus miembros reivindican su autonomía personal como un bien. Han escuchado el llamado de Kant, que los invita a pensar por sí mismos, a abandonar a sus tutores, a comportarse como adultos. Pero al mismo tiempo están dispuestos a "comprometer parte de la autonomía en alguna identidad supraindividual: religiones, asociaciones de la sociedad civil, corrientes filosóficas o políticas, nacionalidades" (93) y gracias a esa disponibilidad están en condiciones de participar en alguna tradición, de compartir sus creencias, ideologías y propuestas, de luchar por sus ideales. Esta articulación entre libertad personal y solidaridad con el grupo, tiene también su correlato en la medida que algunas tradiciones son más críticas respecto de su entorno y otras más proclives a su mantención. El momento crítico y de innovación no es prerrogativa exclusiva de las tradiciones seculares, como tampoco el momento tradicional y conservador lo es de las tradiciones religiosas. La identificación de lo religioso con lo conservador y de lo secular con lo liberal, además de falsa, no nos permite avanzar en lo que me parece el desafío fundamental (94).

Para salir de estos maniqueísmos estrechos conviene acoger las enseñanzas que Paul Ricoeur extrae del debate sostenido por dos grandes filósofos contemporáneos en la década del setenta. La polémica entre Jürgen Habermas y Hans-Georg Gadamer permite apreciar cómo la crítica de las ideologías y la hermenéutica de las tradiciones, además de ser un nuevo episodio de la batalla entre la Ilustración y el

(92) Charles Taylor, "Two Theoriee of Modernity", Hastings Center Report 25, № 2 (1995), 24-33.

(93) Diego García, Marginación o inclusión: responsabilidad de los cristianos, Mensaje, septiembre 2005, 19-20.

(94) Cf. Eduardo Silva, Católicos: más allá de liberales y conservadores, Mensaje, mayo 2005. 
romanticismo, pues encarnan bien la tensión entre el gesto crítico que sospecha y el gesto de reconocimiento que acoge (95), se presuponen mutuamente si quieren ser fecundas. Por un lado se innova siempre respecto de una tradición, pues la libertad está siempre situada, es histórica y concreta; por otro, no puede haber apropiación de una tradición sin la novedad que caracteriza a sujetos libres y críticos, porque siempre que se acoge una tradición, hay alguien que se las apropia, que hace 'suyo', 'propio' lo ajeno. Aún más, tal como no puede haber tradición sin crítica (sin sujetos libres, reflexivos que se la apropian y al hacerlo la renuevan modificándola, purificándola), la crítica misma es también una tradición. Es imposible saltarse la historia y ubicarse en un no lugar, libre de prejuicios, no afectado por ningún sesgo ideológico. Siempre hablamos desde una tradición. La crítica de las ideologías pertenece a la tradición de la Aufklärung y a distintas tradiciones que beben del ideal de la ilustración. Habermas pertenece a esta tradición de la emancipación que es distinta de la tradición de la rememoración, del romanticismo, que sería la tradición a la que pertenece Gadamer. Pero la crítica hunde sus raíces en la más impresionante tradición, aquella de los actos liberadores; a ella pertenecen también la memoria del Éxodo y la memoria de la Resurrección (96). El judeocristianismo tiene en su origen una tradición de emancipación y de aprecio irrestricto a la libertad. Tiene tambien una actitud agradecida por el resto de las tradiciones que lo constituyen, hace memoria de ellas, las actualiza y conserva.

Frente a este panorama de tradiciones simultáneamente en conflicto y diálogo, además de describir con un poco más de detención las transformaciones vividas por las tradiciones religiosas, hemos subrayado el influjo mayor que está teniendo en las pautas de comportamiento de todos los pueblos, la sociedad de mercado globalizado que al promover un individualismo abstracto contribuye justamente a erosionar las identidades colectivas y las pertenencias comunitarias. "La globalización de racionalidad económica vista como epopeya de la autonomía individual, genera en el límite una identidad abstracta, vacía y lábil, de individuos aislados entre sí y que solo se comunican en el plano de su capacidad y desempeño económico" (97). Sin duda cada una de las tradiciones religiosas y seculares tienen aportes específicos e insustituibles que hacer frente a este desafío mayor. Nuestra atención en este artículo se ha centrado

(95) "Este debate pone el juego el gesto filosófico de base: o el reconocimiento [humilde, la confesión] de las condiciones históricas a las que está sometida toda comprensión humana bajo el régimen de la finitud, o bien... [el] gesto de desafío, un gesto crítico... dirigido contra la falsa conciencia, contra las distorsiones de la comunicación humana detrás de las cuales se disimula el ejercicio permanente de la dominación y de la violencia...: o la conciencia hermenéutica o la conciencia crítica" (P. Ricoeur, Herméneutique et critique des idéologies" (1973), Du texte a l'action. Essais d'herméneutique II, Seuil, Paris, 1986, 333). Para Ricoeur el punto es la apreciación diferente de la tradición: apreciación positiva vs apreciación sospechosa. En términos análogos Alejandro Vigo nos habló en el seminario interno de la Facultad de teología de la tensión entre sospecha y caridad presente en todo proceso hermenéutico, que no obliga a excluir una en nombre de la otra sino a dirimir cuál es la más universalisable (cf. Gadamer, "L'universalité du probléme herméneutique" (1965), Archives de philosophie, 1971, 3-13; Habermas, "Revendication d'universalité de 1'herméneutique", Festschrift en honor a Gadamer, titulado Herméneutique et Dialectique I, 1970).

(96) Cf. Paul Ricoeur, "Herméneutique et critique des idéologies" (1973), Du Texte a l'action, 376.

(97) Diego García, Marginación o inclusión: responsabilidad de los cristianos, Mensaje, septiembre 2005,19 
en la importancia que tiene a este objeto la articulación entre cristianismo y modernidad, y lo central que es en el continente la mutua fecundación y enriquecimiento entre la tradición liberal republicana y el catolicismo latinoamericano.

Hemos insinuado algunos límites que apreciamos en la tradición liberal republicana frente a la marea del capital globalizado. Hemos insinuado que el cristianismo tiene algo que aportar de cara a esos límites, siempre y cuando sea capaz de integrar lo mejor de la modernidad. Antes de presentar alguno de los aportes que el catolicismo está llamado a dar, quisiera explicitar un par de aportes que es indispensable recoger de la tradición liberal republicana.

Nos parece que hay dos lecciones, entre otras muchas, que los católicos podemos y debemos aprender del pensamiento liberal y moderno. Se trata más bien de dos búsquedas a las que debemos sumarnos pues son adquisiciones preciosas que nos aporta un liberalismo republicano. La primera es justamente de carácter crítico, pues el liberalismo posee una concepción ética y política de la libertad que critica la dominación, la sacralización y la concentración del poder. La segunda, de carácter constructivo, nos recuerda con Hegel, que "la máxima expresión de la libertad es el derecho" y que solo es posible construir una convivencia con "instituciones justas".

Cualquier crítica del liberalismo, incluida la que postula otro tipo de liberalismo, que sea capaz de articular algunos de los planteos que provienen desde las propuestas comunitaristas y de acoger los aportes de las tradiciones concretas presentes en una situación dada (en nuestro caso los que vienen del catolicismo latinoamericano), debe partir por reconocer su aporte imprescindible a una concepción ética y política de la libertad. Ricoeur nos recuerda que se trata de "la crítica del soberano y de la soberanía concebida como trascendental, en un sentido religioso o no" (98). Crítica contra la dominación, a menudo sacralizada, crítica que con la metáfora del contractualismo nos invita a ver "como" si el poder naciera de un acuerdo libremente consentido, crítica que quiere reducir el poder desde la dominación a la autoridad auténtica. Crítica que termina por ofrecernos la democracia como régimen político. Se trata de una advertencia no menor a cualquier proyecto de liberación: "Si la crítica de la opresión económica y social no pasa por la crítica de la dominación política, y si se pretende ir a la liberación económica por no importa qué camino político, se está condenado a una venganza terrible de la historia: el leninismo es a este respecto la ilustración siniestra. Para occidente el paso por la liberación política es considerado como ineluctable, como nos lo ha continuamente enseñado la catástrofe totalitaria" (99), y como lo hemos experimentado con nuestras dictaduras militares latinoamericanas. Nuestra propia crítica al capitalismo financiero globalizado, no puede olvidar esta lección ni pretender su control y regulación por cualquier medio. Lo que hace atractivo al liberalismo y también al liberalismo económico es su apego y aprecio por la libertad. En este aspecto resulta invencible.

Sin embargo, el propio liberalismo, y aquí en particular la tradición republicana nos ofrece los medios de regular legítimamente la libertad. El mismo Ricoeur define la intensión ética como "el tender a la vida buena con y para los otros en

(98) P. Ricoeur, "Philosophie et liberation", Concordia (Aachen) 22, 1992, 50.

(99) Ibíd., 52. 
instituciones justas" y define las instituciones como "interacciones regladas" (100). El imperativo ético de institucionalizar nuestras interacciones es urgente a dos niveles. Primero en el nivel de la globalización económica, que ya hemos mencionado, donde es imperativo que seamos capaces de construir estructuras políticas, jurídicas y económicas de nivel planetario, capaces de domesticar a este caballo desbocado, que habiendo saltado por encima de las regulaciones estatales solo se deja guiar por la ley del más fuerte. Segundo en el nivel continental, y particularmente al interior de nuestros países, donde uno de los desafíos mayores sigue siendo la carencia y precariedad de nuestras instituciones. Construir institucionalidad, dar solidez a nuestras estructuras de gobierno, acordar procedimientos y normas justas en los distintos ámbitos de la vida son tareas pendientes, imperativos de la modernidad que nos son urgentes. Sin instituciones, es siempre el más fuerte el que gana. La asimetría de poder, de fuerza, de influencia, de dinero solo es posible de ser compensada con instituciones que funcionen y permiten que todos sean iguales ante la regla. En una tierra de privilegiados, de oligarcas que siguen imponiendo su parecer y su cultura, de grandes compadrazgos que influyen en las esferas de poder, de intocables y poderosos que se defienden solos, la ley, felizmente ciega y en lo posible insobornable, es una ventaja para el desvalido, para el que no tiene recomendaciones, ni avales, ni compadres poderosos que influyan por él. La igualdad abstracta de todos, el desaparecer de las particularidades, es en estos casos beneficiosa para quienes no tiene apellidos, ni fundos, ni fondos, ni pedigrí, ni ducados, ni títulos que ostentar, que otros enarbolan para justificar sus privilegios.

\section{Aportes del catolicismo latinoamericano}

Al terminar preguntándonos por los aportes específicos que el catolicismo latinoamericano está en condiciones de ofrecer e insinuar que la trayectoria latinoamericana a la modernidad se enriquece con ellos conviene hacer algunas advertencias. En primer lugar no se trata de un proyecto político católico alternativo, que en una suerte de oportunismo histórico debido a la crisis de la modernidad aprovechara la fragilidad política de nuestras democracias para reivindicar la fortaleza cultural de nuestro "sustrato católico". Tal propuesta como lo advierte Juan Noemi, "se desentiende de la eclesiología de Vaticano II: el servicio al mundo no solo implica hacerse cargo del mundo como un referente externo a la Iglesia, sino que requiere que esta se haga cargo ad intra de su propia mundanidad y laicidad" (101). La valoración de la libertad, la crítica de la dominación, la necesidad de mayor institucionalización no son fenómenos externos a la Iglesia, sino imperativos que le atañen directamente. No pocas veces los cristianos estamos más pendientes de la brizna del ojo ajeno sin reparar en la viga que

(100) Cf. P. Ricoeur, Soi même comme un autre, Paris, Seuil, 1990, 228. Scannone y Hünermann respectivamente nos recuerdan que sin las instituciones "el hombre no puede estar en el mundo con otros y, por lo tanto, ni siquiera ser sí mismo" (Scannone) pues "las instituciones son... figuras de la vida indispensables para estar-en-el-mundo y el estar-con-otros" (Hünermann) (citado por Scannone en "Justicia e injusticia estructural/institucional" (por publicar). Ver también Scannone, "Aportes filosóficos para una teoría y práctica de instituciones justas, Stromata 50 (1994), 157-173.

(101) Cf. Juan Noemi, ““Inculturación del evangelio”. Recepción teológico-crítica de una propuesta de Santo Domingo", Teología y Vida 34 (1993) 315-325. 
nubla nuestra mirada. "En no pocos documentos eclesiales hay una clara desproporción entre la criticidad de la realidad de América Latina y la criticidad a la realidad eclesial. Doble estándar que no se adentra en una cultura que se trató de desconocer y que no detecta autocríticamente aquello que condujo a la automarginación de la Iglesia con respecto al mundo y la cultura moderna y que no se sustenta como denuncia profética sino como actitud miope y torpemente autodefensiva" (102).

En segundo lugar se trata de aportes ético-políticos y no de autoafirmación de temáticas exclusivamente culturales o religiosas. Ciertamente la inclusión de la perspectiva cultural y religiosa en los diagnósticos eclesiales ha constituido un avance respecto de análisis que solo consideraban las variables socioeconómico-políticas. "Sin embargo en la medida que se especifica demasiado apresuradamente nuestro ethos como cultura religiosa o católica puede generarse un nuevo estrechamiento y miopía, fomentarse un provincianismo teológico abocado unilateralmente a la reflexión de temas religiosos y no considerar el fenómeno cultural en su real amplitud y autonomía" (...). "La teología no es la racionalización de fenómenos que se consideran religiosos, sino reflexión de los signos de los tiempos bajo la luz del Evangelio" (103). Son muchas las razones que nos impiden postular una suerte de apoliticidad o neutralidad de la Iglesia y nos obligan a reconocer la dimensión política del cristianismo. En nuestra pretensión teológica de auscultar la situación del catolicismo latinoamericano, se contiene una clara intencionalidad política.

Al preguntarnos por los aportes ético-políticos que el catolicismo puede ofrecer a nuestra región, estamos reconociendo aspectos fundamentales que es posible detectar con distintos niveles de intensidad en todo el abanico plural de versiones del catolicismo. Se trata justamente de los aspectos donde encontramos "la unidad de la diferencia" y que tienen la virtud no solo de convocarnos, afirmando una identidad que parece tan fragmentada sino también de convocar a otros en una tarea que nos es común. No nos estamos refiriendo al símbolo de la fe ni a sus explicitaciones en el dogma que son los que en definitiva nos dan la unidad y nos mantienen en la comunión, sino a aportes ético-políticos que nos parecen relevantes a los desafíos que hemos auscultado en el tiempo presente y en la situación continental. Solo nos limitaremos a esbozar algunos, deteniéndonos muy brevemente en algunos de ellos. Un trabajo más completo, al que estas líneas quieren invitar, se beneficiaría si pudiéramos distinguir en una especie de matriz cuatro tipos de aportes:

- $\quad$ los aportes que el catolicismo puede ofrecer en grado eminente (porque es muy propio suyo o porque no son muchos los que lo pueden ofrecer con ese nivel de intensidad),

- aquello en lo que esta en condiciones de hacer aportes relevantes junto con otros,

- $\quad$ aquello en lo que no es capaz pero podría llegar a hacerlo

- $\quad$ y aquello en lo que más bien dificulta y obstruye (104).

(102) Ibíd.

(103) Cf. J. Noemi, “Teología en Latinoamérica. En el cincuentenario de “Anales””, Teología y Vida 31 (1990), 337-343.

(104) Estas notas están tomadas de las intervenciones de Raúl González, s.j., en el XXI Encuentro del Equipo jesuita latinoamericano de reflexión filosófica, San Miguel, julio 2004. 
El catolicismo puede aportar en grado eminente:

- una constante preocupación por los pobres y los más desvalidos,

- $\quad$ un discurso sobre la sexualidad y la vida familiar,

- la posibilidad de reconciliar en una tradición religiosa, fe y razón,

- $\quad$ una estética devocional que nos conecta simbólicamente con el pasado.

Aportes que nos parecen eminentes pues son muy peculiares suyos y no siempre están presentes con tanta fuerza en otras tradiciones. La preocupación por la equidad y los más desfavorecidos la encontramos en la tradición republicana y con más fuerza en algunas de las tradiciones románticas. Un discurso sobre la sexualidad y la vida familiar solo es compartido por los evangélicos y es una ausencia notable en el resto de las tradiciones seculares, que comienzan a incorporarlo solo con la aparición reciente del feminismo. La tentación de fideísmo a la que se ve expuesta toda tradición religiosa es resistida muy claramente por el catolicismo es su denodado esfuerzo por vincular fe y razón. Lo que hemos llamado estética devocional, que es la capacidad que tienen las tradiciones de rememorar su historia, de conmemorar los acontecimientos fundamentales, de celebrar sus héroes, en definitiva de vincularse simbólicamente con el pasado está también presente en las celebraciones cívicas y militares de la tradición republicana.

Otros aportes relevantes que el catolicismo latinoamericano puede ofrecer junto con otros es su contribución al estado de derecho y la enorme red de instituciones sociales que posee, en educación, en salud, etc. En esta preocupación por lo institucional y por crear instituciones justas puede unir sus esfuerzos a lo mejor de la tradición moderna en una tarea que hemos señalado indispensable en América Latina. Su opción preferencial por los pobres y la vinculación que afirma entre fe y razón son recursos que le dan especiales habilidades en esta tarea. En virtud de estos mismos recursos se esperaría que pueda aportar mejor al debate moral, que se ve asolado por varios peligros que se deben evitar al ser capaces de distinguir los planos: que las convicciones se transformen en fanatismo, que lo ético se reduzca a lo jurídico, que se mediatice el debate moral, etc.

Desde esta u otras ordenaciones es posible un trabajo hermenéutico que no solo ordene el mapa de los aportes que están llamados a dar las distintas tradiciones latinoamericanas, sino también la interpelación que cabe hacer desde el Evangelio y los imperativos éticos del presente a las variadas formas de vivir el catolicismo.

Quisiéramos terminar señalando un aporte que es muy propio del cristianismo y que quizás no está dando con la intensidad que la situación que hemos descrito requiere: la construcción de vínculos no abstractos. Ello solo es posible si los sujetos se reconocen por su pertenencia a una realidad que los antecede. "Lo que nuestra época no capta, es precisamente lo que la Iglesia quiere representar y no siempre puede: la antecedencia de la comunidad a las personas. Si en la modernidad las personas pretenden elegir sus pertenencias (a grupos, comunidades, redes, etc.), la Iglesia les recuerda que hay un vínculo originario con Dios y entre los hombres que hace posible estas elecciones" (105). Antes de poder elegir, somos elegidos y recibidos en una comuni-

(105) J. Costadoat, "Católicos en democracia", Mensaje, septiembre 2005, 16. 
dad. El sujeto se constituye a partir de otro, puede hablar porque ha sido capaz de escuchar lo que otro le ha hablado, puede amar porque ha sido amado, puede darse porque ha sido sujeto del don. Solo así es posible que existan sujetos agradecidos que reconocen que la mayor parte de lo que tienen les ha sido dado

Este reconocimiento no será posible si no se reequilibra la relación entre el individuo y la comunidad, si no se modifica una ideología, un orden y un modelo, que no solo no ofrece seguridad, ni protección, ni refugio, sino que disuelve los vínculos, que desconoce las identidades colectivas y que sostiene que cada individuo lucha en solitario o a lo más formando parte de alguna tribu de turno.

La concepción de libertad del humanismo cristiano permite una mejor articulación entre lo personal y lo comunitario y es más radical que el momento de la elección. Se funda en un don recibido creatural y redentor, pues la vida se recibe como regalo y la libertad como llamado que libera para ordenar las elecciones hacia el bien. Que la persona humana se autocomprenda como libre, dotada de razón, capaz de creación y de responsabilidad, es una genuina creación cristiana que proviene de ser hijos de Dios, adoptados en Cristo e inspirados por el Espíritu, siendo responsables delante del juicio del Dios trino. Una libertad así concebida es la de un sujeto que no se constituye a partir de sí mismo, sino de otro, que no es una monada cerrada y autónoma, sino abierto a los demás; no se trata de una independencia autárquica, sino de una interdependencia constitutiva que vive de los vínculos sociales y de lazos que parten como dados y llegan a ser libremente asumidos. El cristianismo afirma que la libertad se constituye a partir de otro, de otros y de Otro, y que por ello se transforma en amor y amistad, justicia y búsqueda del bien común, en solidaridad compasiva y en fraternidad de los hermanos de un mismo Padre (106).

La preocupación por los más desfavorecidos y por la afirmación de vínculos que nos constituyen son caminos por los que puede volver a transitar un catolicismo social y un cristianismo comunitario. Aportes muy peculiares del catolicismo pues ambos beben de la virtud incluyente e integradora del Evangelio. Una preocupación por la fraternidad que no se hace a expensas de la libertad, pues en los dos casos la libertad es el asunto central: hacer real la libertad de quienes no tienen oportunidades ni posibilidades de elegir; enraizar la libertad a los vínculos que la hacen posible. Aportes que le permiten encontrarse con otras tradiciones, y en particular como lo hemos subrayado aquí, con la tradición moderna, en la medida que ambas son capaces de recoger lo mejor de la otra superando así sus respectivos límites. Aportes, finalmente, pertinentes a los macro desafíos que describíamos en la primera parte. Una comunidad política global capaz de institucionalizar el capitalismo globalizado es un modo de responder a los problemas de justicia. Comunidades y tradiciones que poseen identidades y que estructuran su convivencia con arreglo a instituciones que permiten compartir sentidos es la condición de posibilidad de la vivencia de la fe. La preocupación por la fe y la justicia, preocupaciones teológicas por excelencia, han sido las claves a la hora de elegir los fenómenos que nos parecen más acuciantes y de señalar los recursos que las distintas tradiciones latinoamericanas pueden ofrecerse como lo mejor de ellas mismas. 


\section{RESUMEN}

En la tarea de recoger los aspectos más significativos de la realidad latinoamericana, que una interpretación teológica del presente histórico concreto debiera tener en cuenta, se vuelve inevitable enfrentarse a la cuestión de la instalación de la modernidad en el continente. Cuestión más bien de la "crisis de la modernidad", que debe entenderse considerando simultáneamente dos asuntos: la crisis que ella ha provocado en muchos aspectos de la cultura tradicional, incluida la cultura cristiana y eclesial tradicional latinoamericana, y la crisis que la propia modernidad experimenta en sí misma, crisis que se intenta balbucear agregando el incierto prefijo "pos", a la llamada posmodernidad. Después de reconocer la existencia de "múltiples modernidades", pues otras culturas no occidentales se modernizan a su manera sin necesidad de reproducir todos los rasgos de la modernidad europea, se nos plantea la pregunta por las peculiaridades de la trayectoria latinoamericana a la modernidad. Para contestarla hemos de considerar los rasgos comunes actuales de aquello que se está instalando (I) y las características del lugar en el que se instala (II). Son apenas un par de esbozos de las cuestiones que respectivamente debemos tener en cuenta si nos fijamos en el tiempo presente y aquellas que hemos de considerar atendiendo a la situación del continente. Respecto de lo primero hacemos un rápido esbozo destacando los procesos de globalización económica y de individualización. Respecto de lo segundo atendemos a las tradiciones aún vivas del continente, seculares y religiosas. Son justamente estas tradiciones, y entre ellas la articulación fecunda y deseable entre cristianismo y modernidad, las que pueden responder a los acuciantes desafíos del de la globalización. Se analizan en particular los aportes y posibilidades que ofrece el catolicismo a esta modernidad a la latinoamericana, que no será posible sin un cristianismo a la altura de los tiempos y una modernidad con la hondura religiosa del continente (III).

\section{ABSTRACT}

In the task of retrieving the most significant aspects of Latin American reality, which a theological interpretation of the historical, concrete present ought to take into account, confronting the question of the installation of modernity on the continent becomes unavoidable. The question, in fact, of a "crisis of modernity" must be understood taking simultaneously into consideration two matters: the crisis that it has provoked in many aspects of traditional culture, including Latin American traditional Christian and ecclesial culture, and the crisis that modernity in itself experiences, stuttering away by trying to add the uncertain prefix "post" to so-called "post-modernity". After recognizing the existence of "multiple modernities"-for other non-occidental cultures are modernizing themselves in their own manner without necessarily reproducing all the traits of European modernity-the question is raised for us by the peculiarities of the Latin American trajectory towards modernity. In order to answer this question, we have to take into consideration the common, current features of that which is being installed (I), and the characteristics of the place in which the installation takes place (II). These are hardly more than a couple of outlines of the questions that we must respectively take into account if we pay attention to the present time, and that we have to consider in attending to the situation of the continent. In regard to the first, we make in this article a rapid sketch emphasizing the processes of economic globalization and of individualization. Regarding the second question, we attend to the traditions that are still alive on the continent, both secular and religious. Precisely these traditions, and among them the fruitful and desirable articulations between Christianity and modernity, are those which can respond to the demanding challenges of the ethos of globalization. The contributions and possibilities that Catholicism offers this modernity and Latin America are analyzed in particular, which would not be possible without a Christianity that rises to the occasion and a modernity with the religious depth that this continent offers (III). 